\title{
Effects of diadochokinetic rate on vocal fundamental frequency and intensity in normally speaking young adults
}

Oya Topbas

West Virginia University

Follow this and additional works at: https://researchrepository.wvu.edu/etd

\section{Recommended Citation}

Topbas, Oya, "Effects of diadochokinetic rate on vocal fundamental frequency and intensity in normally speaking young adults" (2010). Graduate Theses, Dissertations, and Problem Reports. 2981.

https://researchrepository.wvu.edu/etd/2981

This Thesis is protected by copyright and/or related rights. It has been brought to you by the The Research Repository @ WVU with permission from the rights-holder(s). You are free to use this Thesis in any way that is permitted by the copyright and related rights legislation that applies to your use. For other uses you must obtain permission from the rights-holder(s) directly, unless additional rights are indicated by a Creative Commons license in the record and/ or on the work itself. This Thesis has been accepted for inclusion in WVU Graduate Theses, Dissertations, and Problem Reports collection by an authorized administrator of The Research Repository @ WVU. For more information, please contact researchrepository@mail.wvu.edu. 
Effects of Diadochokinetic Rate on Vocal Fundamental Frequency and Intensity in Normally Speaking Young Adults

$$
\text { Oya Topbaş }
$$

Thesis submitted to the College of Human Resources and Education at West Virginia University in partial fulfillment of the requirements for the degree of

\author{
Master of Science \\ in \\ Speech-Language Pathology
}

Kenneth O. St. Louis, Ph.D., Chair

Robert F. Orlikoff, Ph.D.

Norman J. Lass, Ph.D.

Department of Speech Pathology and Audiology

\author{
Morgantown, West Virginia \\ 2010
}

Key words: Diadochokinetic Rate, Speech Rate, Fundamental frequency, Intensity

Copyright 2010 Oya Topbaş 


\title{
ABSTRACT \\ Effects of Diadochokinetic Rate on Vocal Fundamental Frequency and Intensity in Normally Speaking Young Adults
}

\author{
Oya Topbaş
}

It has been commonly assumed that as people speak faster, they speak in higher vocal fundamental frequencies. Since the frequency and intensity often vary together, vocal intensity is expected to increase with speaking rate as well. The purpose of this study was to explore how speaking rate affects vocal fundamental frequency and intensity during diadochokinetic speaking tasks in normal speaking adults. Twenty-four normal

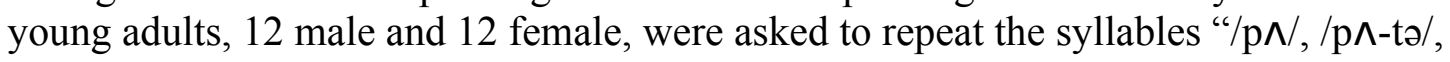
and $/ \mathrm{p} \wedge$-tə-kə/" at a self-selected comfortable rate, then at a slow rate modeled about one syllable per second, and finally at their maximum rate. It was hypothesized that increasing the speaking rate from slow to comfortable, and comfortable to fast would increase fundamental frequency and intensity. All experimental speech segments were recorded to the Computerized Speech Lab (CSL) program through a head-mounted microphone. The results showed significant increases in fundamental frequency for both males and females as a function of rate increase for all three diadochokinetic tasks, as hypothesized. However, intensity did not increase as a function of rate increase but varied with syllables and sex of the participants. The results suggest that fundamental frequency increases independent of intensity as a function of rate increase in diadochokinetic tasks. It is likely that rapid speech fosters an increase in the longitudinal tension in the vocal folds, which therefore increases fundamental frequency while the vocal intensity is maintained. 


\section{Acknowledgements}

First, I would like to thank my thesis chair, Dr. Ken St. Louis, for his mentorship, guidance, motivation, sincerity, patience, and encouragement. His support, his willingness to teach me research, his advice, and his friendship has helped me immensely. I especially would like to thank him for believing in me, and in this project; and helping "me" believe that I could do it. I started with no knowledge and experience in research and application; I now have a major accomplishment. Doing and writing this thesis has been a huge learning experience for me; I am extremely thankful to him for teaching me.

Next, I would like to thank the other members of my thesis committee, Dr. Robert Orlikoff and Dr. Norman Lass, for all of their help and suggestions. I have been very lucky to have them on my thesis committee. It has been a pleasure working with them.

I would also like to thank all of my dear friends who participated in and helped me with the study. I highly appreciate their willingness and support.

Last but not least, I would like to thank my parents, Seyhun and Seyhan, for giving me the most wonderful opportunity to study here in the USA, thousands of miles from Turkey and away from their sight... They have always given me love and independence and have taught me to stand on my own feet. They have always supported and trusted me, no matter what. I am very thankful, for without their support and encouragement, I would not be here in wild and wonderful West Virginia and in West Virginia University. Without their knowledge, their guidance in my life, and their genuineness as parents, I would not be as self-confident and as content in my life as I am. I find myself extremely lucky to be their daughter, and I am extremely proud to have 
DDK Rates, Frequency, and Intensity iv

such incredible parents. "Teşekkürler anneciğim ve babacı̆̆ım." (Thank you mom and dad). 


\section{TABLE OF CONTENTS}

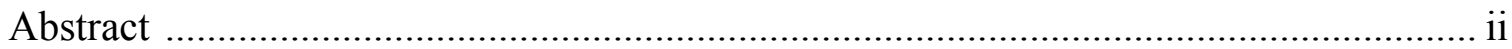

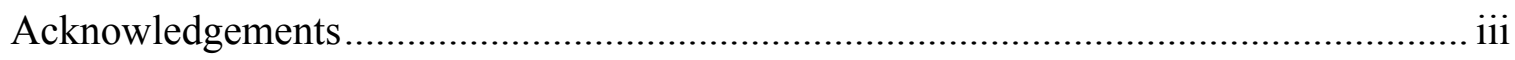

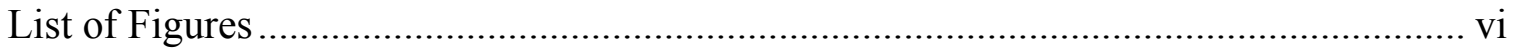

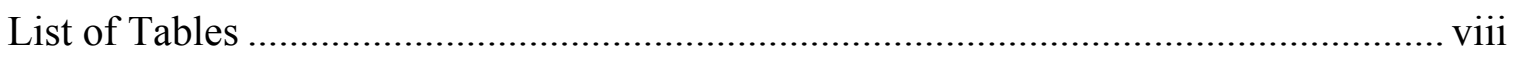

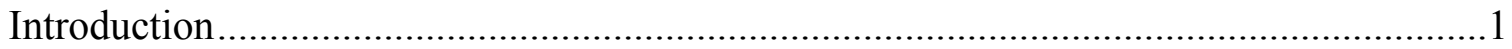

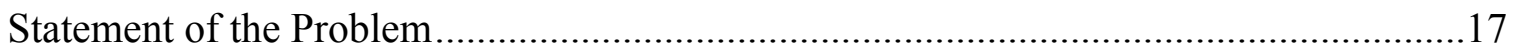

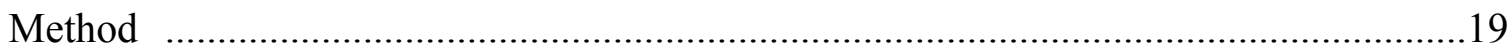

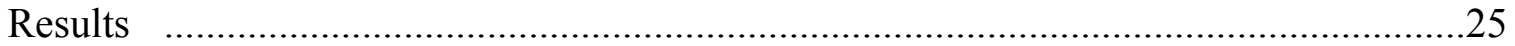

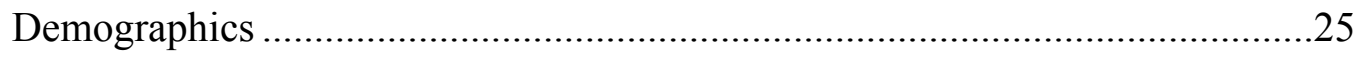

Speaking Speed in Syllables per Second .................................................25

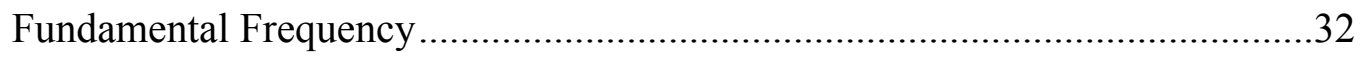

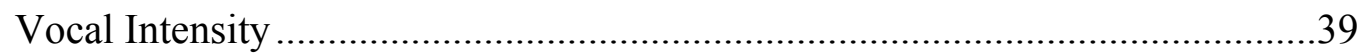

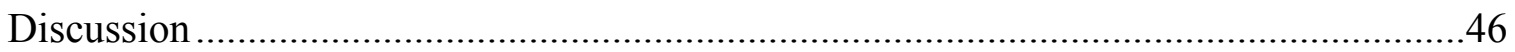

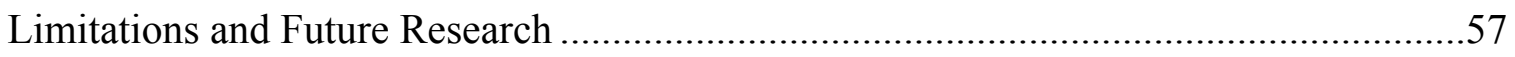

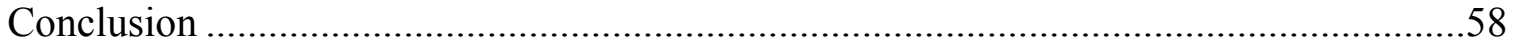

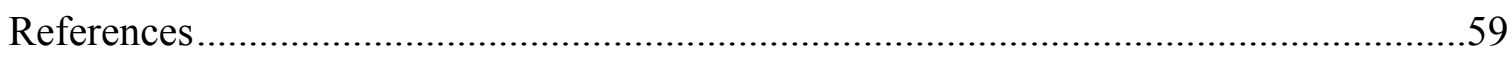

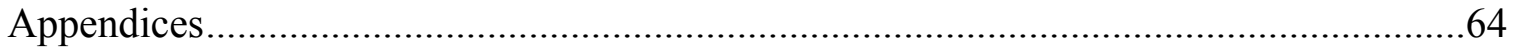




\section{LIST OF FIGURES}

Figure 1. Means and standard deviations for syllables per second (S/s) for three rate conditions and three syllable complexity conditions for male and female participants

Figure 2. Mean syllables per second ( $\mathrm{S} / \mathrm{s})$ for males and females for the three rate conditions averaged across the three rate conditions. .30

Figure 3. Mean syllables per second (S/s) for males and females for the three syllable conditions averaged across the three syllable conditions

Figure 4. Means and standard deviations for fundamental frequency $\left(\mathrm{F}_{o}\right)$ for three rate conditions and three syllable complexity conditions for male and female participants

Figure 5. Mean fundamental frequency $\left(\mathrm{F}_{\boldsymbol{o}}\right)$ for males for the three rate conditions averaged across the three syllable conditions

Figure 6. Mean fundamental frequency $\left(\mathrm{F}_{o}\right)$ for females for the three rate conditions averaged across the three syllable conditions

Figure 7. Mean fundamental frequency $\left(\mathrm{F}_{\boldsymbol{o}}\right)$ for males for the three syllable conditions averaged across the three rate conditions

Figure 8. Mean fundamental frequency $\left(\mathrm{F}_{\boldsymbol{o}}\right)$ for females for the three syllable conditions averaged across the three rate conditions

Figure 9. Means and standard deviations for vocal intensity (dB SPL) for three rate conditions and three syllable complexity conditions for male and female participants 
Figure 10. Mean intensity (dB SPL) for males and females for the three rate conditions

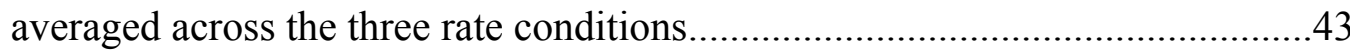

Figure 11. Mean intensity (dB SPL) for males and females for the three syllable conditions averaged across the three syllable conditions 


\section{LIST OF TABLES}

Table 1. Means, standard deviations, and ranges for speed of talking in syllables per second (S/s) for three rate conditions and three syllable complexity conditions for male and female participants.

Table 2. Probability values for post hoc pairwise t-test contrasts using the Tukey correction for DDK rates, syllables, and sex for syllables per second (S/s)......28

Table 3. Probability values for post hoc pairwise t-test contrasts using the Tukey correction for DDK rates, syllables, and sex for speed of talking in syllables per second $(\mathrm{S} / \mathrm{s})$ .29

Table 4. Means, standard deviations, and ranges for fundamental frequency $\left(\mathrm{F}_{o}\right)$ for three rate conditions and three syllable complexity conditions for male and female participants

Table 5. Probability values for post hoc pairwise t-test contrasts using the Tukey correction for DDK rates, syllables and sex for fundamental frequency $\left(\mathrm{F}_{\boldsymbol{o}}\right)$....34

Table 6. Pairwise comparisons of DDK rates, syllables, and sex for fundamental frequency $\left(\mathrm{F}_{\boldsymbol{o}}\right)$

Table 7. Means, standard deviations, and ranges for vocal intensity (dB SPL) for three rate conditions and three syllable complexity conditions for male and female participants

Table 8. Probability values for post hoc pairwise t-test contrasts using the Tukey correction for DDK rates, syllables and sex for vocal intensity (dB SPL)

Table 9. Pairwise comparisons of DDK rates, syllables, and sex for vocal intensity (dB

SPL) 


\section{Introduction}

Speaking rate or speed of talking is sometimes included on perceptual evaluation forms for suspected voice disorders. For example, on the Buffalo Voice Profile (Wilson, 1979), the examiner is directed to score "Rate" as "Normal," "Fast," or "Slow" and then to evaluate either of the latter two categories on a 1-7 Likert scale with 1 representing a "slight deviation" and 7 a "severe deviation." Interestingly, none of the perceptual scales that included speaking rate (Calvert \& Silverman, 1975; Pindzola, 1987; Wilson, 1979) provided a rationale for including it in the scales.

Given that rate is considered by some authorities to be relevant to voice, it is important to understand the effects of rate on voice (Stemple, Glaze, \& Klaben, 2000). Potentially, rate could affect at least three important aspects of the voicing: vocal frequency, vocal intensity, and breathing. Stemple, Glaze, and Klaben (2000) point out that persons who speak at a fast rate are more likely to have laryngeal or voice pathologies than those who speak at a normal rate. In these cases, producing speech too rapidly appears to be related to using the laryngeal mechanism incorrectly, thus causing vocal hyperfunction. One contributing factor when one talks too fast is that the speaker may not be using optimal breath support during speaking. Limited breath support may increase laryngeal muscle tension can strain the vocal mechanism and contribute to voice problems such as vocal nodules or vocal polyps. Therapy strategies involving reducing the rate have been used in hyperfunctional voice problems. Rate reduction techniques have also been used in hypofunctional voice disorders such as related to Parkinson's disease. Reducing the speech rate and increasing vocal intensity, and increasing the articulatory contacts can result in increased intelligibility and improved voice (Boone, 
McFarlance, \& Von Berg, 2005; Schulz, 2002). Stemple et al. (2000) indicate that speaking rate may also be judged to be "monotonous," contributing to a lack of speech and voice variability. Finally, varying the rate has been used in chanting as a voice therapy technique in voice resonance problems (Stemple, Glaze, \& Klaben, 2000).

\section{Rate}

Rate refers to the speed at which a person speaks. Generally, rate is considered in the contexts of speech fluency or motor speech disorders. Ordinarily, speech rate is expressed as the number of events divided by the elapsed time. Following are typical measures used followed by the kinds of speaking tasks used to assess rate.

\section{Measurement of Speaking Rate}

\section{Words (Syllables) Per Minute}

Words or syllables per minute (W/M; S/M) are measures of rate that generally refer to the speed with which a speaker produces multiple sentences that include normal pauses and normal disfluencies, such as "uh" and "like." Obviously, W/M involves counting the number of words and dividing by the speaking time elapsed. S/M is similar, but it involves counting the number of syllables uttered and dividing by elapsed speaking time. By definition, $\mathrm{S} / \mathrm{M}$ rates are higher than $\mathrm{W} / \mathrm{M}$ rates because a given sample of speech cannot have fewer words than syllables since a word must consist of at least one syllable. A problem that occurs in comparing $\mathrm{S} / \mathrm{M}$ rates across investigations is that inconsistencies exist regarding the question of whether or not syllables not generally considered as meaningful are counted. Ordinarily, W/M rates only include meaningful words, although inclusion or exclusion of word fillers such as "well," "you know," and "like" affect these rates as well (Costello \& Ingham, 1984; Guitar, 2006). 
Fairbanks (1960), a classic proponent of the W/M measure, recommended measuring rate as follows. A passage that has a specific number of words (e.g., a 300word passage) is read under standard conditions and is timed. The number of words is divided by the time elapsed, and the rate is calculated in W/M.

Pindzola, Jenkins, and Lokken (1989) measured S/M in a study of normal speaking rate in two tasks: (a) telling a story from sequential picture arrangement and (b) answering open-ended questions. Their participants included 30 children in 3-, 4- and 5year age groups. The authors counted syllables and measured audio-playbacks of talking times with a stopwatch in minutes and seconds. They found no significant differences in either overall speaking rate or articulatory rates across the three age groups.

\section{Syllables per Second}

Clearly, one could divide W/M or S/M by 60 to get syllables per second (S/s); yet, the $\mathrm{S} / \mathrm{s}$ measure is not ordinarily used in this way. Instead, it typically involves evaluating only perceptually fluent syllables in short utterances that contain no pauses to obtain a measure of rate of speaking only. Names for this measure of rate include "articulation rate" or "phone rate" (St. Louis \& Ruscello, 2000). As an example, Sawyer, Chon, and Ambrose (2008) studied the influences of rate, utterance length, and grammatical complexity on stuttering-like disfluencies in children. Their methodology considered rate in terms of perceptually fluent syllables divided by the duration in seconds of utterances

after removing all the instances of disfluencies and pauses greater than 250 milliseconds. Barreto and Ortiz (2008) also used articulatory rate, measured as the mean number of syllables produced per second, excluding any pauses and separating the articulatory sequences. They measured the duration of each utterance in milliseconds and calculated 
mean velocity by dividing total number of syllables in three lists of speech stimuli (words, sentences and nonsense syllables) by the total time. Using the "Grandfather Passage” (Fairbanks, 1960), in a study of speaking rate, Wohlert and Hammen (2000) calculated articulatory rate as words per minute after pause duration had been subtracted from the overall duration.

\section{Speaking Tasks Used in Measurement of Speaking Rate}

\section{Meaningful Speech}

In the above-mentioned study by Wohlert and Hammen (2000) instructed 20 participants were told to read the passage first at a habitual rate, next at a slower rate, and finally at a faster rate. As noted, articulatory rate was calculated as in words per minute. This is an example of oral reading prose. Saxena (1992) used four different sentences in measuring participants' speech rate, such as "The book on the table was a gift from my mother." The participants were asked to read these sentences at three different speeds: a normal rate, a slower rate, and a faster rate. Sturm and Seery (2007) studied rate in conversational speech samples of more than 300 words. Children were asked open-ended questions during a conversation with a researcher. Sturm and Seery (2007) also used a story generation task evoked by 25 pictures to measure children's speech rate. The participants were instructed to first look through all the pictures before beginning the narrative monologue. If needed, they used a two-minute thinking time before telling the story.

\section{Diadochokinetic (DDK) Tasks}

Diadochokinesis refers to performing rapid alternating movements of the speech articulators (Duffy, 2005). In speech-language pathology, diadochokinetic (DDK) 
evaluations measure clients' ability to perform rapid repetitions of relatively simple patterns as in "p^-tə-kə" (Baken \& Orlikoff, 2000; Fletcher, 1972; St. Louis \& Ruscello, 2000). DDK rates are useful for determining the speed and the regularity of the movements of the jaw, lips, and tongue in motor speech disorders (Duffy, 2005). These rapid alternating movement tasks have been applied to speech-language pathology using a variety of nonspeech and speech movements. In many diagnostic protocols utilizing an oral mechanism examination, nonsense syllables such as "p $\wedge$, , "t $\mathrm{\wedge}$, " and " $k \wedge$ " and multisyllable sequences such as "p^-tə" or "p $\wedge$-tə-kə" are used to investigate maximum DDK rates (Hutchinson, Hanson, \& Mecham, 1979; Peterson \& Marquardt, 1981; St. Louis \& Ruscello, 2000).

There are two ways that a clinician can determine DDK rates. Both procedures require the client to repeat the desired unit at a maximum rate but either for a specific number of seconds or for a specific number of repetitions. In the first procedure, a timer is switched on for the specified period of time while the repetitions are recorded. For the second procedure, which is known as "time-by-count," a timer is started, predetermined repetitions produced at a maximum rate are counted, and the timer is stopped at that point. With the time-by-count procedure, the examiner records the time elapsed. Fletcher (1972), Hutchinson et al. (1979), and St. Louis and Ruscello (2000) recommended the time-by-count procedure, because it does not require the examiner to carefully monitor the timer while counting the repetitions. It is simpler to do than counting the number of DDK repetitions in a set period of time (Fletcher, 1972; St. Louis \& Ruscello, 2000). 


\section{Perceptual Ratings}

As noted, it is common in several perceptual evaluation forms for clinical evaluations of suspected voice disorders to include a score for the person's speaking rate. The rationale for including rate in these perceptual scales is either typically omitted (e.g., (Buffalo Voice Profile [Wilson, 1979]; A Voice Assessment Protocol for Children and Adults [VAP] [Pindzola, 1987]) or briefly explained. In the latter case, Calvert and Silverman (1975) stated that an excessively fast speaking rate may influence other variables of speech and voice. On the Buffalo Voice Profile (Wilson, 1979), "rate" is scored as "normal," "fast," or "slow" with a 1-7 Likert scale where 1 equals a "slight deviation" and 7 a "severe deviation." Wilson (1979) highlighted a suggestion to check rate when there was a suspicion of a voice disorder associated with a motor speech disorder.

St. Louis, Myers, Faragasso, Townsend, \& Gallaher (2004) included perceptual ratings of rate in an investigation of cluttered speech from two youths. The study also included perceptual judgments of speech naturalness, articulation, language, and disfluency. Oral reading, monologue, and dialogue speaking tasks were evaluated wherein listeners used a 1-9 equal appearing interval scale to score their judgments. The study included three measures of intrajudge reliability: percentages of ratings that differed by none, one, two, or more scale values between six repeated samples, mean differences between the first and second judgments for the repeated samples; and correlations between the two judgments. The results for rate are relevant to this review. Twenty-nine and $35 \%$ of the respective judgments were identical for the repeated samples, $65 \%$ and $69 \%$ were within \pm 1 scale value, $83 \%$ and $87 \%$ were within \pm 2 scale 
values, and $94 \%$ and $96 \%$ were within \pm 3 scale values. The mean difference between first and second judgments for rate was nearly identical for one clutterer, i.e., 0.08 , but were the largest of all the judgments, i.e., 0.47 scale values for the other clutterer. Mean correlations for rate judgments were .66 and .62 , lowest of the five dimensions for one participant and second to lowest for the other. Even so, these judgments were considered to be satisfactory, given previous research in 1-9 scale ratings (e.g., Martin, Haroldson, \& Triden, 1984).

\section{Voice}

\section{Fundamental Frequency $\left(\mathbf{F}_{o}\right)$}

Vocal frequency refers to the number of vibratory cycles per second of a person's voice, expressed in hertz $(\mathrm{Hz})$. Frequency is primarily responsible for the perception of pitch. A listener's perception of a speaker's pitch depends on the fundamental (lowest) frequency $\left(\mathrm{F}_{o}\right)$ in the speaker's voice. When the frequency of vibration is increased, we perceive it as a rise in pitch, and when the frequency is decreased, we hear a lowering of pitch. Importantly, however, the relationship is not linear between perceived pitch and frequency (Raphael, Borden, \& Harris, 2007).

Fundamental frequency is predictably different among the voices of men, women, and children. Vocal folds are generally longer and thicker in males than in females, which cause the males' fundamental frequency to be lower than females; conversely, vocal folds are shorter and thinner in females, causing females' fundamental frequency to be higher than males. The typical mean speaking fundamental frequency for young men is about $125 \mathrm{~Hz}$ and about $225 \mathrm{~Hz}$ for young women (Hollien, Hollien, \& de Jong, 1997:

Stoicheff, 1981). In early childhood, boys and girls have similar fundamental frequencies, 
i.e., near a range of $241 \mathrm{~Hz}$ to $322 \mathrm{~Hz}$ (Hall \& Yairi, 1992). At puberty, their fundamental frequencies descend, males much more than females to adult levels. And in advanced age, female fundamental frequency typically drops to $190-200 \mathrm{~Hz}$ while male's fundamental frequency increases to about $145 \mathrm{~Hz}$ (Abitbol, Abitbol, \& Abitbol, 1999). Fundamental frequency is related physiologically to vocal fold length, thickness, and elasticity. In a given individual larynx, longer, thinner, or tense folds vibrate at a faster rate than thicker or more relaxed folds. Subglottal air pressure also exerts a slight influence on fundamental frequency. Near the upper end of the natural pitch range, where the elasticity of the vocal fold is increased, the glottal resistance increases. Therefore, an increased subglottal air pressure is required to produce higher frequencies. Increased tension of the vocal folds requires greater air pressure to set the vocal folds into vibration (Boone, McFarlane, \& Von Berg, 2005).

Obviously, fundamental frequency is not static. Aside from mean values for a speaker, fundamental frequency constantly changes according to the intonation patterns of words and syllables in the speaker's utterances (Raphael, Borden, \& Harris, 2007).

\section{Vocal Intensity}

Intensity (or amplitude) or sound pressure is also a physical property of the acoustic signal measured in decibels $(\mathrm{dB})$ in reference to a standard, such as sound pressure level (SPL) (Gelfand, 2007). The psychological sensation of loudness of a sound is related to its intensity. As the intensity increases, the judged sound gets louder, and vice versa. Again, intensity and loudness are not linearly related. Subglottal air pressure is the primary determinant of vocal intensity, as well as a secondary determinant of vocal fundamental frequency, as noted above (Baken \& Orlikoff, 2000). 


\section{Vocal Frequency and Intensity}

It is clear that there is a strong relationship between fundamental frequency and intensity, and, therefore, between loudness and pitch. In spite of the aforementioned determinants, loudness is influenced by the fundamental frequency, and the perceived pitch of a voice changes as the intensity changes (Orlikoff \& Kahane, 1996). These combined influences are partly due to respiration. If subglottal air pressure is increased without muscular adjustments of the vocal folds, the fundamental frequency as well as the intensity increases (Raphael, Borden, \& Harris, 2007). In other words, fundamental frequency is secondarily influenced by vocal intensity.

\section{Speech Respiration}

For this discussion of rate, frequency, and intensity, two aspects of speech breathing become relevant. First, a relatively constant supply of subglottal pressure is required to drive the vocal folds and maintain a given vocal intensity level. Second, the sustained pressure requires a level of micro-control. As well as speakers can maintain the constant pressure that is needed for phonation they are also capable of rapidly and briefly changing the pressure for linguistic purposes. With quick bursts of pressure speakers can achieve rapid and brief increases in vocal intensity and vocal frequency (Seikel, Drumright, \& Seikel, 2004).

Subglottal air pressure and frequency change. Increasing one's frequency requires increasing the longitudinal tension of the vocal folds. Increasing the aerodynamic driving force will cause the vocal folds to separate further and more quickly. This causes them to snap back together more quickly, therefore increasing the frequency about 3 to $5 \mathrm{~Hz}$ per $\mathrm{cm} \mathrm{H}_{2} \mathrm{O}$ (Baken \& Orlikoff, 1987). In other words, 
subglottal air pressure has only a slight effect on frequency increase (Seikel, Drumright, \& Seikel, 2004).

Subglottal air pressure and intensity change. Subglottal air pressure provides the energy to raise the intensity or the power of the phonation. Therefore, increased intensity is directly caused by increased subglottal air pressure (Seikel, Drumright, \& Seikel, 2004). Importantly, however, the relationship between intensity and subglottal air pressure is not linear (Baken \& Orlikoff, 2000). For example, Titze and Sunberg (1992) reported that the intensity increases by 8 to $9 \mathrm{~dB}$ each time the subglottal air pressure is doubled. Isshiki (1964) found in a single male subject that the subglottal air pressure measured by tracheal puncture varied from 3 to $25 \mathrm{~cm} \mathrm{H} 2 \mathrm{O}$ as the intensity increased from 65 to $95 \mathrm{~dB}$.

Subglottal air pressure, intensity, and frequency. The tendency for frequency and intensity to increase together is a natural phenomenon. Increases in intensity and fundamental frequency are controlled independently, but depend on the same mechanisms: longitudinal tension of the vocal folds, medial compression of the folds, and subglottal pressure. It is possible to increase intensity without increasing the frequency but, to do so, is difficult. Nevertheless, trained or well-controlled speakers can do it (Seikel, Drumright, \& Seikel, 2004).

\section{Rate and Voice}

Little research on how speech rate affects fundamental frequency and vocal intensity has been published. Studies of disordered populations exist, but such research has not been carried out with "normal” populations. Raphael, Borden, and Harris (2006) 
called for research to clarify the interaction of muscular and non-muscular contributions to frequency change. Atkinson (1978) suggested that the relative contributions of various muscular and non-muscular forces may vary in different parts of an individual's pitch range.

Watson, Ciccia, and Weismer (2003) examined the relationship of speech breathing to selected acoustic properties of speech. They hypothesized that initiating speech from different lung volumes would affect different elements of the acoustic output. Eight normal women between 18-35 years of age participated in their study. To determine lung volume initiation levels, each participant's breathing was monitored by the Respitrace. The study involved a series of vital capacity maneuvers (to measure lung volume displacement), breath holding maneuvers and 24 oral-reading tasks of different lengths and different phonetic contents. Average sound pressure level increased consistently from low lung volume levels to high levels. On the average, fundamental frequency increased consistently by $24 \mathrm{~Hz}$ from lower to higher lung volume levels.

Stathopoulos and Sapienza (1993) studied 30 male and 30 female participants from equally distributed age groups: 4 year olds, 8 year olds, and adults. Each participant produced repetitions of $/ \mathrm{pa} /$ at soft, comfortable, and loud levels at a rate of 1.5 syllables per second. Simultaneous aerodynamic, acoustic, and kinematic measurements from the laryngeal and respiratory systems were made in order to study mechanisms for changing vocal intensity. The authors hypothesized that as the vocal intensity increased, amplitudebased flow measures and fundamental frequency would increase. For all of the groups, there were significant increases in intensity with a doubling of the tracheal pressure. An interaction between sex and age showed significantly higher fundamental frequencies for 
women than men, but it did not show significantly higher fundamental frequencies for girls than boys. For all children and adult groups, fundamental frequency increased from soft to loud speech. However, fundamental frequency increased when vocal intensity decreased from comfortable to soft speech in women and men. In that case, the tracheal pressure decreased when the fundamental frequency increased.

Wohlert and Hammen (2000) examined the average EMG amplitude from surface electrodes over perioral muscles (e.g., right upper lip, left upper lip, right lower lip and left lower lip) during connected speech in order to clarify possible differences in neuromuscular control for changes in speech rate and loudness. Ten male and 10 female university students read aloud the "grandfather passage" at "habitual," "fast" and "slow" rates and as "precisely" as possible. Their intensity was measured by CSpeech (used in analyzing acoustic signal) as the difference in average voltage level as in $\mathrm{dB}$. Wohlert and Hammen found that the average amplitude of the EMG signal was greater for fast speech than for slow speech, and it was greater for loud or precise speech than for slow speech. Nevertheless, the results also showed that facial EMG amplitude increases could be independent of increases in intensity and speech rate. For precise speech, EMG amplitude was increased, rate was decreased, and the intensity remained at habitual levels. The data also revealed that the increases in speech rate were accompanied by increases in intensity, and decreases in speech rate were accompanied by decreases in intensity.

Dromey and Ramig (1998) measured the effects of changing vocal sound pressure level (dB SPL) and rate on respiratory, phonatory, and articulatory behavior during sentence production. Five men and 5 women repeated a sentence 10 times in various rate 
and intensity conditions (e.g., normal rate, slower rate, faster rate, normal loudness, twice as loud as normal, and half as loud as normal). Changes were measured both for fundamental frequency and intensity on the CSpeech software. For both male and female speakers, fundamental frequency increased for loud speech, but stayed more or less constant for soft speech. Mean intensity increased with rate, and the intensity increased more for fast speech than normal and slow rates. In male speakers, also, mean fundamental frequency changed as a function of rate, and fundamental frequency variability in semitone standard deviation increased with increasing rate. The rate changes for females were not reported.

Plant and Younger (2000) investigated the interaction between subglottic air pressure, fundamental frequency, and vocal intensity during voice production. This study is relevant in that their design permits one perspective of the effect of rate on these variables. Subglottic air pressure was measured directly by puncture of the cricothyroid membrane in nine healthy male participants between 23 to 43 years of age. The vocal tasks were the repetitions of the syllables /pa/ and /i/ at rates of approximately 1.5-2.0 syllables per second. In their study, at low intensities, fundamental frequency was independent from subglottic air pressure, but at higher intensities there was a general trend that the fundamental frequency increased with higher subglottic air pressure, although vocal intensity almost always increased with subglottic air pressure. At high intensities, as the subglottic air pressure increased, both fundamental frequency and intensity increased.

Lundy, Roy, Xue, Casiano, and Jassir (2004) carried out a study of patients with adductor spasmodic dysphonia (ADSD), voice tremor (Tremor), and spastic dysarthria in 
amyotrophic lateral sclerosis (ALS). Their purpose was to measure "strained, strangled, tremulous" vocal qualities in order to differentiate them with acoustic and motor speech parameters such as fundamental frequency, intensity, intonation stimulability, DDK rate, and standard syllabic rate. DDK rate was based on the analysis of rapid production of the syllable "puh"; standard syllabic rate was based on the analysis on a patient's ability to produce an all-voiced sample without unnecessary pauses (e.g., "We knew you were away all year."). Eight patients per group, 24 participants in total, participated in this study. The results revealed that the mean intensity level for all DDK syllable repetitions were significantly reduced for all three disorder groups, compared to normal scores. Also, both the ALS and tremor groups had increased variability of intensity levels during rapid syllable repetition in comparison with the ADSD group.

In a complex, multivariate study, Linville, Skarin and Fornatto (1989) demonstrated that reading rate was related to fundamental frequency stability and maximum vocal intensity. Twenty healthy women between $67-86$ years participated in the study. Vocal performance measures, such as the production capabilities of the mechanisms related to intensity range, pitch range, and maximum phonation time; and acoustic measures such as fundamental frequency stability and intensity during reading and sustained vowel productions were measured. The Visi-Pitch (Kay Elemetrics) was use to measure the frequencies. Factor analyses were conducted to determine the relationship among vocal performance measures, acoustic data, and reading rate. Reading rate was found to increase or decrease proportionally with fundamental frequency stability and maximum vocal intensity. 
Shanks (1970) investigated the effects of variations in perceived vocal pitch and loudness upon rapid repetition of the syllable /ha/ in 40 young normal adult female participants. They repeated /ha/ rapidly at low, comfortable, and high pitches while altering their loudness from low to comfortable, and then comfortable to high at each pitch level. The results showed a relationship between changes in pitch and loudness of vocalization and rates syllable repetition. Rates were highest when the participants used comfortable pitch and loudness levels. Rates were slower as loudness was reduced at comfortable pitches. With high loudness at low pitches, rates became significantly slower, and when high pitches were employed, rates were significantly increased as phonation became louder at high pitches.

This search of the literature revealed only one obscure study from India directly testing the hypothesis of this study (see below). Saxena (1992) investigated the effects of different speaking rates on vocal intensity and fundamental frequency "topline." Fundamental frequency topline refers to the peak values of the fundamental frequency in selected key words in sentences read aloud by Saxena's 20 participants. The participants were asked to read a list of sentences in three different speed rates: "normal," "faster," and "slower." It was hypothesized that if the verbal material was uttered at a faster than normal rate of speaking, the peak fundamental frequency would increase and if the verbal material was uttered at a slower rate, the peak fundamental frequency would decrease. The hypothesis was confirmed: the peak fundamental frequency was highest when reading aloud at a fast rate of speech, and, conversely, was lowest during a slow rate of reading. 
Summary. In Plant and Younger's (2000) study, as subglottic air pressure increased at high intensities, both fundamental frequency and intensity increased. Dromey and Ramig (1998) found that mean intensity increased with rapid speech rate. For males, fundamental frequency changed as a function of rate, and fundamental frequency variability in semitone standard deviation increased with increasing rate. Wohlert and Hammen (2000) reported that the increases in speech rate were accompanied by increases in vocal intensity and vice versa. In the Lundy, Roy, Xue, Casiano, and Jassir (2004) study, ALS and tremor patients—-but not ADSD patients—-had increased variability of intensity level during rapid syllable repetition. Linville, Skarin, and Fornatto (1989) found that reading rate was related to fundamental frequency stability and maximum vocal intensity. Shanks (1970) found that with high loudness at low pitch, rates became significantly slower. By contrast, high frequencies were associated with significantly increased rates as phonation became higher in intensity. Saxena (1992) found that reading rate was positively related to increases and decreases in fundamental frequency.

All of these studies show that there is a strong relationship between fundamental frequency and vocal intensity as they rise and descend relatively. Moreover, speaking rate was observed to increase when using higher intensities and higher fundamental frequencies. Notably, fundamental frequency was observed to be the highest when reading aloud at a fast rate of speech (Saxena, 1992). Accordingly, it is plausible to assume that there is a causative or correlative connection between a fast rate of speech, higher fundamental frequency, and greater intensity. Yet, this is not seen in all the studies, due no doubt to some combination of different experimental tasks, variability it 
subject performance, and dependent variables. Further, some of these studies demonstrate a relationship between rate of speech and either fundamental frequency or vocal intensity in people with voice disorders. However, none of the studies clearly demonstrate that a fast rate of speech influences the fundamental frequency to go higher and the vocal intensity to get louder in a population with "normal" speech. Therefore, this study explores the relationship between rate of speech and both fundamental frequency and vocal intensity.

\section{Statement of the Problem and Purpose}

The literature suggests that while one is talking, and as speech rate gets faster, both fundamental frequency and vocal intensity increase, at least in some voicedisordered individuals. However, there is little such information on the relationship between rate and fundamental frequency or intensity in normal speakers.

The purpose of this study, therefore, is to begin to fill in this gap and explore the influence of diadochokinetic (DDK) rate on fundamental frequency and vocal intensity in participants who have "normal" speech. The three research questions were:

1. At maximum DDK rate, will the speakers' fundamental frequency be higher and will their vocal intensity be greater than their comfortable and slow DDK rates of speech? The hypothesis is that both will be higher at maximum rates.

2. At a modeled slow DDK rate, will the speakers' fundamental frequency be lower and will their vocal intensity be lower than their comfortable and fast DDK rates of speech. The hypothesis is that both will be lower at modeled slow rates. 
3. Are there any identifiable differences among one, two, or three syllable tasks?

The hypothesis is that there will be differences in measurements within each rate for fundamental frequency and intensity among the three syllable tasks. 
DDK Rates, Frequency, and Intensity 19

\section{Method}

\section{Participants}

The author recruited 24 normal, young adult speakers between ages 20-29 years as research participants. The participants consisted of 12 males and 12 females from a mid-Atlantic university town. Students from majors other than speech-language pathology in West Virginia University or other individuals were asked to volunteer for the study from solicitations by e-mail, written or verbal announcements, or personal invitations.

Potential study participants were screened to meet inclusion criteria described in more detail below. Appendix A lists six "Voice Related Questions" designed to provide information about vocal use, voice problems, or other potentially confounding variables. All of the participants' answers are shown in Appendix B. One participant had undergone a tonsillectomy in childhood, two participants reported mild childhood asthma, one participant listed brief vocal training in middle school, and two participants reported brief church choir training in youth. About $60 \%$ of the participants reportedly sang a few times a week either at home or in their cars for about 10-20 minutes. Two participants were involved in professional athletics (i.e., karate, personal training, and dancing), and eight participants played wind instruments nonprofessionally. 
DDK Rates, Frequency, and Intensity 20

\section{Inclusion Screening}

Only potential participants who were regarded to have normal voice, speech, and language were recruited. Upon agreeing to sign an IRB consent form and meeting the criteria of the Voice Related Questions (Appendix A), all potential participants read and signed the form and then underwent hearing screenings. Next, they were tape recorded while conversing with the author, reading orally, and prolonging two vowel sounds (see below). A perceptual component of the inclusion screening consisted of Pass/Fail criteria for "articulation," "language," "fluency," “resonance," “pitch," “loudness," "quality," and "rate." As more thoroughly explained in the Reliability section below, potential participants were required to receive a "Pass" in all areas to qualify as a study participant (See Appendix C, Perceptual Screening Form). All participants passed air-conduction hearing screening (Appendix D, Pure Tone Hearing Screening Form) at $20 \mathrm{~dB}$ at frequencies $1000 \mathrm{~Hz}, 2000 \mathrm{HZ}, 3000 \mathrm{~Hz}$, and $4000 \mathrm{~Hz}$ in order to be included in the study (ASHA, 1997).

\section{Reliability}

As noted, the conversation, oral reading, and vowel prolongation tasks were taperecorded. Working independently, a graduate student in speech-language pathology was asked to complete the same screening form for all of the participants while listening to the tape recordings to verify the judgments of the author. If the graduate student's judgments did not match with those of the author, a third speech-language pathology graduate student independently judged the sample in question. For any participant whose normality was in question, if two out of three of the independent verifiers did not score a "Pass" for all items, then that participant was not included in the study and another 
participant was selected. Appendix E shows the Pass/Fail criteria for all potential and final participants. Three potential participants were eliminated by these procedures, one for fluency, one for quality, and one for fluency, pitch, and quality.

\section{Experimental Procedures}

\section{Testing Procedure}

Diadochokinetic (DDK) sequences. A script of the testing procedure is outlined in Appendix F. Participants first produced DDK tasks at a self-selected "comfortable" rate, then at a "slow" rate after a rate modeled (by the author) at about one syllable per second, and then at their "maximum" rate. The DDK task consisted of the following repetitive productions: "puh" as in /p $/$, then "puh-tuh" as in /p $\Lambda$-tə/ and finally "puh-tuh-kuh" as in $/ \mathrm{p} \wedge-\mathrm{t} \partial-\mathrm{k} \partial /$. Each repetition task lasted about 10 seconds. If participants jumbled up the syllables or seemed to strain to produce them at their fastest rate for any of the four groups of syllables, they were asked to repeat the syllables at "a little less than their maximum rate."

Microphone placement. All experimental speech segments were recorded to the Computerized Speech Lab (CSL) program through a MicroMic C520 head-mounted microphone that had a dynamic range of $20 \mathrm{~Hz}$ to $20,000 \mathrm{~Hz}$. The participants were instructed to wear the head-mounted microphone from the beginning until the end of the session and were told to neither touch nor change the position of the microphone. Before the first DDK task, the distance was measured between the closed lips and the microphone to be $5 \mathrm{~cm}, \pm 3 \mathrm{~mm}$ or about 2 inches and was placed at the side of the mouth. 
DDK Rates, Frequency, and Intensity 22

Speaking Tasks. A one-minute conversation between the author and the participant consisted of the following questions: "What is your major/job?" and "Can you describe the city/ town you live in or can you describe your hometown?" Next, the participant read the first paragraph of the "Rainbow Passage" (Fairbanks, 1960) (Appendix G). Finally, the participant was asked to prolong the sounds $/ \mathrm{a} /$ and $/ \mathrm{u} /$ for 3-5 seconds each. As noted, the participant was recorded during these three speaking tasks. The author filled in the aforementioned perceptual screening form while all three speaking tasks were ongoing.

\section{Analysis of Results}

Measurement of fundamental frequency and intensity. Audio signals were simultaneously recorded to the Computerized Speech Lab (CSL) Model 4500 (Kay Pentax, 2008). The CSL is a hardware and software computer system used to record and to display acoustic parameters of speech and voice signals for linguistic, forensic, and communication sciences applications. Real-Time Pitch (RTP) (Model 5121) is a supplementary program of the CSL program and was used to analyze the voice samples in this study (Kay Pentax, 2008). The RTP program is specifically designed to provide true real-time, visual feedback of the speech parameters of pitch, energy, and timing. It provides true real-time performance with pitch extraction for each glottal pulse. In this study, to measure the fundamental frequency and intensity, after the syllables were bracketed with cursors, the "statistics" option was selected from the menu. Results for both fundamental frequency and intensity were saved into the computer for further analysis. 
Measurement of speed in syllables per second $(S / s)$. Each experimental segment involved only one breath group. For all syllable production segments, speaking speed in syllables per second (S/s) was calculated by counting all the intensity peaks within syllable traces from the beginning to the end of the entire breath group bracketed by the cursors. The total number of syllables was divided by the number of seconds in the segment, generating a syllable per second $(\mathrm{S} / \mathrm{s})$ value for each syllable production task. This analysis, carried out as a control procedure, was necessary to document that participants did, in fact, speak slowest in the slow condition, faster in the comfortable condition, and faster yet in the fast condition.

Measurement of DDK syllables. Each DDK task lasted approximately 10 seconds in one breath group, and syllables in the middle of each breath group were analyzed to avoid potential artifacts associated with the task onset and ending. Appendix $\mathrm{H}$ provides a schematic of the syllables selected for each syllable sequence. To analyze the same number of syllables, the following procedures were undertaken. A 7- to 8-second window in the middle of a breath cycle was selected for analysis after discounting the first and last second. For the /pN/ syllable at all rates, 6 consecutive syllables, i.e., 6 /pN/ syllables, were selected at the middle of the 7-8 second segment, as much as possible with three syllables before and three syllables after the midpoint. The mean fundamental frequency and intensity of these six syllables were isolated for analysis. For $/ \mathrm{p} \wedge$-tə/ sequences at all rates, again, 6 consecutive syllables, i.e., 3 /p^-tə/ syllable trains, were taken from the middle of the 7-8 second segments in the same way for mean fundamental frequency and 
intensity analysis. For /p^-tə-kə/ at all rates 6 consecutive syllables, i.e., 2 /p^-tə-kə/ syllable trains, from the middle of the 7-8 second segments were analyzed.

\section{Statistical Analysis}

This study explored how DDK rate of speech and complexity of DDK syllable production, as independent variables, affected two dependent variables, i.e., fundamental frequency and vocal intensity. As a control procedure, the study also compared the speed of productions in the various conditions. The data were subjected to both descriptive and inferential statistics. Descriptive analyses included means, standard deviations, and ranges for each measure reported in tabular formats. Means and standard deviations are also reported in graphic formats.

Inferential analyses involved running multivariative analysis of variance (MANOVA) separately for fundamental frequency, for vocal intensity, and for syllables per second with three levels for rate (slow, comfortable, and fast) and three levels syllable

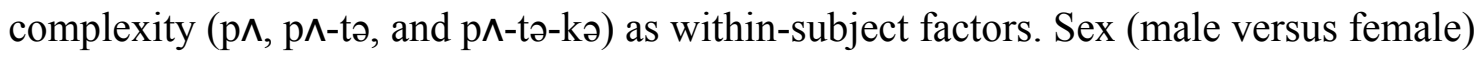
was a between-subject factor. MANOVA is appropriate to use in this design (Nie \& Hull, 1968) and permits comparison of the dependent variables as well as the interactions among them. For statistically significant main effects, post hoc pairwise $t$ tests for nonindependent samples were carried out between various factors or interactions using the Tukey correction (Gay, Mills, \& Airasian, 2006). 
DDK Rates, Frequency, and Intensity 25

\section{Results}

\section{Demographics}

As reported in the Method section, 24 normally speaking, young adult speakers from a mid-Atlantic university town, 12 males and 12 females between the ages of 20-29 years, participated in this study. Male and female participants were matched for age such that each pair was within three years of the same age. Detailed information about each participant is shown in Appendix I. The ages for males ranged from 20 to 29, with a mean age of 23.42, and for females, ages ranged from 20 to 28 , with a mean of 22.08 . All participants were either students with majors other than speech-language pathology and audiology, or were nonstudents working in other fields. As noted above, all were judged to be normal speakers and had normal hearing.

\section{Speaking Speed ${ }^{1}$ in Syllables per Second (S/s)}

Speaking speed was analyzed as a control procedure. The study investigated the effects of DDK rates on voice. It was assumed that actual speed of speaking would vary as expected, but the actual differences between the DDK rates could not be predicted. Moreover, to better interpret potential difference across the various syllable sequences, speed of producing each of them was considered an important control procedure as well. Appendix J displays individual results for speed of producing DDKs in S/s. Table 2 lists mean S/s values, standard deviations, and ranges separately for males and females for the three experimental rates (slow, comfortable, and fast) and for the three DDK syllable sequences $(\mathrm{p} \wedge, \mathrm{p} \wedge$-tə, and $\mathrm{p} \wedge$-tə-kə) within each rate.

\footnotetext{
${ }^{1}$ To enhance reading clarity, "speed" is used for speaking "rate" in this case because "rate" is used mainly in this thesis to refer to the three experimental conditions consisting of "slow," "comfortable," and "fast."
} 
Figure 1 shows mean results and standard deviations from Table 1 for the three rates and, within each one, the three DDK syllable tasks. To assist the reader in separating the two within-subject factors, rate and syllables, the means are also shown in Figures 2 and 3, averaged first by rate across syllables, and then by syllables averaged across rates.

The data were subjected to MANOVA separately for S/s with three levels for the within-subject factor of rate, three levels for the within-factor of syllable complexity, and two levels for the between-factor of sex. Components of the MANOVA are shown in Table 2. Using the Tukey correction, pairwise $t$ tests for non-independent samples were carried out between various means. Table 3 lists the probability values for the post hoc contrasts for the significant changes in $\mathrm{S} / \mathrm{s}$ between DDK rates. 
Table 1: Means, standard deviations, and ranges for speed of talking in syllables per second $(S / s)$ for three rate conditions and three syllable complexity conditions for male and female participants.

\begin{tabular}{|c|c|c|c|c|c|c|c|}
\hline \multirow{3}{*}{$\begin{array}{l}\text { DDK Rate } \\
\text { Condition }\end{array}$} & \multirow{3}{*}{$\begin{array}{c}\text { DDK } \\
\text { Sequence }\end{array}$} & \multicolumn{6}{|c|}{ Syllables Per Second (S/s) } \\
\hline & & \multicolumn{3}{|c|}{ Male } & \multicolumn{3}{|c|}{ Female } \\
\hline & & Mean & SD & Range & Mean & SD & Range \\
\hline \multirow{3}{*}{ Slow } & $\mathrm{p} \wedge$ & 0.78 & 0.10 & $0.62-1$ & 0.78 & 0.10 & $0.67-0.9$ \\
\hline & $\mathrm{p} \wedge$-tə & 0.85 & 0.12 & $0.62-1$ & 0.78 & 0.11 & $0.62-1$ \\
\hline & $\mathrm{p} \Lambda$-tə-kə & 0.89 & 0.14 & $0.64-1.09$ & 0.83 & 0.12 & $0.69-1$ \\
\hline \multirow{3}{*}{ Comfortable } & $\mathrm{p} \Lambda$ & 1.70 & 0.58 & $1.1-2.63$ & 1.65 & 0.45 & $1.1-2.67$ \\
\hline & $\mathrm{p} \wedge$-tə & 1.65 & 0.50 & $1.10-2.71$ & 1.55 & 0.36 & $1.11-2.29$ \\
\hline & $\mathrm{p} \Lambda$-tə-kə & 1.75 & 0.40 & $1.20-2.44$ & 1.54 & 0.37 & $1.09-2.00$ \\
\hline \multirow{3}{*}{ Fast } & $\mathrm{p} \wedge$ & 5.62 & 1.25 & $3.13-7.00$ & 5.32 & 0.58 & $4.33-6.25$ \\
\hline & $\mathrm{p} \wedge$-ta & 7.52 & 1.34 & $5.67-9.60$ & 6.71 & 0.91 & $5.33-8.29$ \\
\hline & p $\Lambda$-tə-kə & 6.70 & 0.99 & $4.88-8.25$ & 6.39 & 0.89 & $5.14-8.00$ \\
\hline
\end{tabular}


DDK Rates, Frequency, and Intensity 28

Table 2: Probability values for post hoc pairwise t-test contrasts using the Tukey correction for DDK rates, syllables and sex for syllables per second ( $S / s)$.

\begin{tabular}{|c|c|c|c|c|c|}
\hline $\begin{array}{c}\text { Source of } \\
\text { Variance }\end{array}$ & Factors & $\mathrm{df}$ & $\begin{array}{c}\text { Mean } \\
\text { Squares }\end{array}$ & $\mathrm{F}$ & $\mathrm{p}$ \\
\hline \multirow{4}{*}{} & Rate & 2 & 648.426 & 1170.566 & $.000^{*}$ \\
\cline { 2 - 6 } & Error (Rate) & 44 & .554 & & \\
\cline { 2 - 6 } & Syllable & 2 & 5.438 & 20.780 & $.000^{*}$ \\
\cline { 2 - 6 } $\begin{array}{c}\text { Within } \\
\text { Subject }\end{array}$ & Error (Syllable) & 44 & .262 & & \\
\cline { 2 - 6 } & Rate vs. Syllable & 4 & 5.711 & 23.670 & $.000^{*}$ \\
\cline { 2 - 6 } & Rate vs. Sex & 2 & 2.313 & 4.176 & $.022^{*}$ \\
\cline { 2 - 6 } & Syllable vs. Sex & 2 & .268 & 1.024 & .368 \\
\cline { 2 - 6 } & $\begin{array}{c}\text { Rate vs. Syllable vs. } \\
\text { Sex }\end{array}$ & 4 & .339 & 1.406 & .239 \\
\cline { 2 - 6 } & $\begin{array}{c}\text { Error (Rate vs. } \\
\text { Syllable) }\end{array}$ & 88 & .241 & & \\
\hline \multirow{2}{*}{$\begin{array}{c}\text { Between } \\
\text { Subject }\end{array}$} & Sex & 1 & 3.072 & 3.066 & .094 \\
\cline { 2 - 6 } & Error & 22 & 1.002 & & \\
\hline \multirow{2}{*}{$*$}
\end{tabular}

*Statistically significant $(\alpha=.05)$ 
Table 3: Probability values for post hoc pairwise t-test contrasts using the Tukey correction for DDK rates, syllables and sex for speed in syllables for second $(S / s)$.

\begin{tabular}{|c|c|c|c|c|c|}
\hline DDK Rates & $\mathrm{p}$ & DDK Syllables & $\mathrm{p}$ & Sex & $\mathrm{p}$ \\
\hline $\begin{array}{c}\text { Slow vs. } \\
\text { Comfortable }\end{array}$ & $.000^{*}$ & $\mathrm{p} \wedge$ vs. $\mathrm{p} \wedge$-tə & $.000^{*}$ & $\begin{array}{c}\text { Male vs. } \\
\text { Female }\end{array}$ & .094 \\
\hline Slow vs. Fast & $.000^{*}$ & $\mathrm{p} \wedge$ vs. $\mathrm{p} \wedge$-tə-kə & $.000^{*}$ & & \\
\hline Comfortable vs. Fast & $.000^{*}$ & $\mathrm{p} \wedge$-tə vs. $\mathrm{p} \wedge$-tə-kə & .085 & & \\
\hline
\end{tabular}

*Statistically significant $(\alpha=.05)$

Figure 1: Means and standard deviations for syllables per second (S/s) for three rate conditions and three syllable complexity conditions for male and female participants.

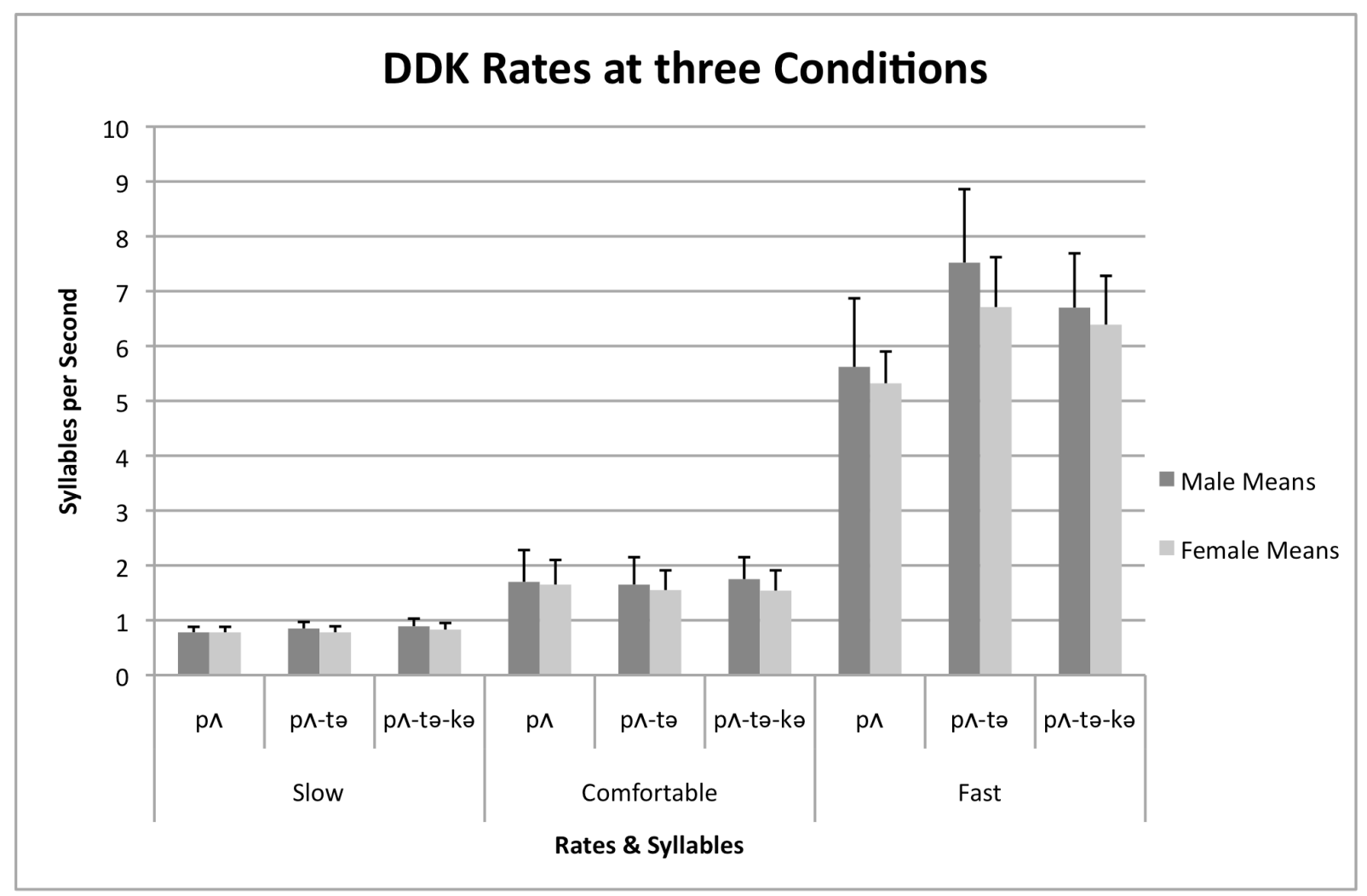


Figure 2. Mean syllables per second (S/s) for males and females for the three rate conditions averaged across the three syllable conditions.

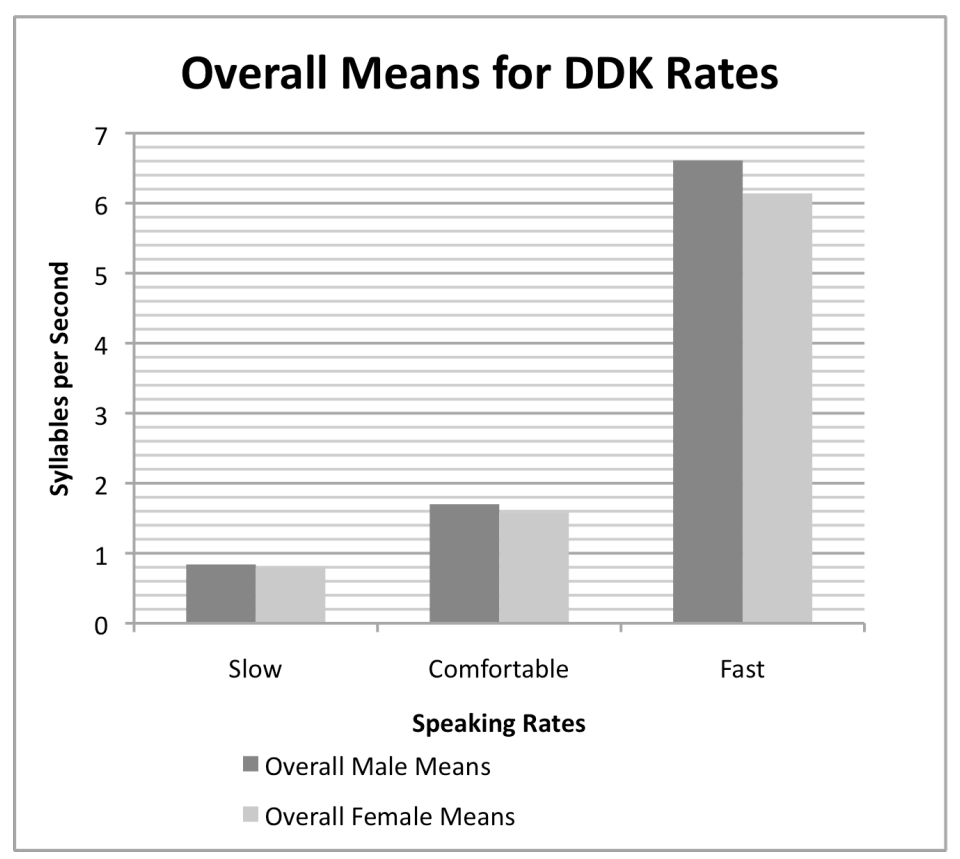

Figure 3. Mean syllables per second (S/s) for males and females for the three syllable conditions averaged across the three rate conditions.

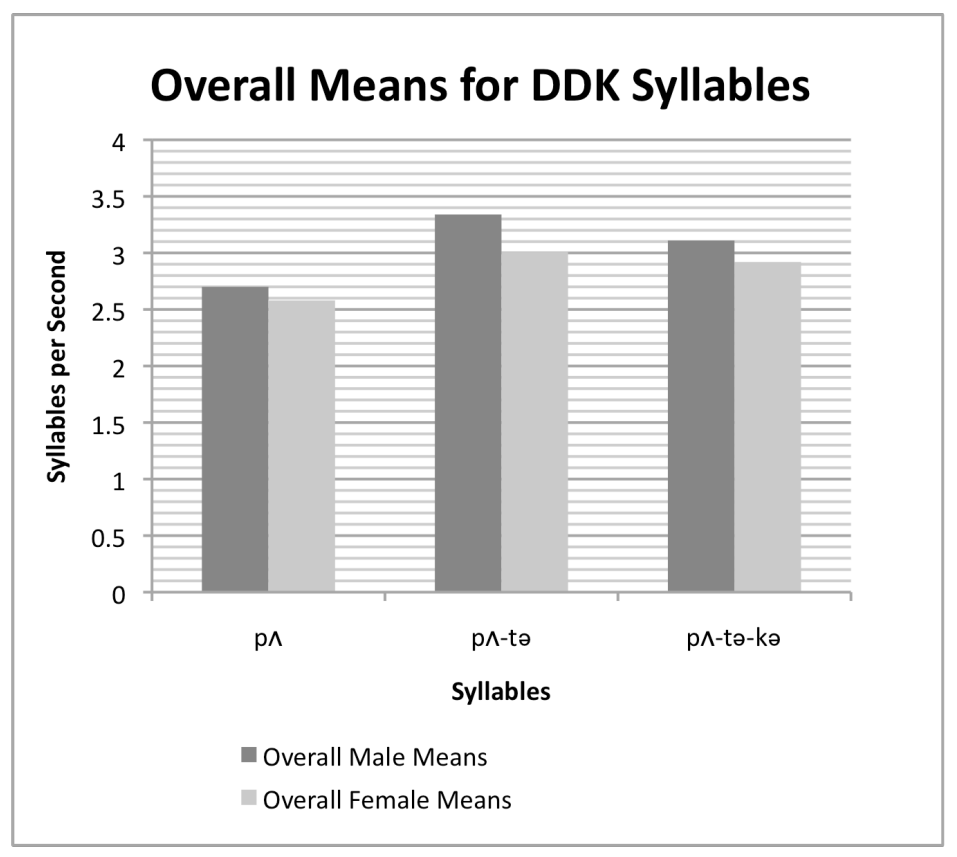


The MANOVA reveals a statistically significant change $(\alpha=.05)$ in $\mathrm{S} / \mathrm{s}$ for the main factors of rate $(\mathrm{df}=2 ; \mathrm{F}=1171 ; \mathrm{p}<.001)$ and syllables $(\mathrm{df}=2 ; \mathrm{F}=20.780 ; \mathrm{p}<$ 001). There was also a significant rate by syllable interaction $(\mathrm{df}=4 ; \mathrm{F}=23.670 ; \mathrm{p}<$ .001 ). Post hoc t test contrasts (Table 3 ) indicated that speaking speed significantly increased as participants' speaking rates increased from slow to comfortable $(\mathrm{p}<.001)$ and from comfortable to fast. There was a difference in speed of speaking between males and females did not reach significance $(p=.094)$ : however, this can be interpreted as a nonsignificant trend for females producing DDKs slower than males. It is likely that for this reason that Table 2 revealed a significant rate by sex interaction $(\mathrm{df}=2 ; \mathrm{F}=4.176 ; \mathrm{p}$ $=.022$ ). More specifically, as shown in Figure 2, the females were noticeably slower for the fast rate.

Post hoc contrasts summarized in Table 3 also reveal significant differences between $\mathrm{p} \wedge$ and $\mathrm{p} \wedge$-tə $(\mathrm{p}<001)$, and between $\mathrm{p} \wedge$ and $\mathrm{p} \wedge$-tə-kə $(\mathrm{p}<001)$. No significant differences existed in $\mathrm{S} / \mathrm{s}$ between $\mathrm{p} \wedge$-tə and $\mathrm{p} \wedge$-tə-kə $(\mathrm{p}=.085)$. These are clearly seen in Figure 3 .

Together, the three graphs confirm visually that the number of syllables produced in the three rate conditions were different as expected. The means for slow rates were slightly less than $1 \mathrm{~S} / \mathrm{s}$, about twice as high for comfortable rates, and about 8 times higher for fast rates. 
DDK Rates, Frequency, and Intensity 32

\section{Fundamental Frequency}

The reader is reminded that fundamental frequency was measured using the RTP program of the Kay Pentax CSL as follows. After six syllables were identified with the cursors, the "statistics" option was selected from the RTP menu. Next, the results of the fundamental frequency were saved into the computer for further analyses.

Individual fundamental frequency results for each participant are presented in the Appendix K. Means, standard deviations, and ranges for the fundamental frequency in each DDK condition are displayed in Table 4, and means and standard deviations are shown in Figure 4. MANOVA results are shown in Table 5, and $t$ test pairwise contrasts using the Tukey correction are shown in Table 6. 
Table 4: Means, standard deviations, and ranges for fundamental frequency (Hz) for three rate conditions and three syllable complexity conditions for male and female participants.

\begin{tabular}{|c|c|c|c|c|c|c|c|}
\hline \multirow{3}{*}{$\begin{array}{c}\text { DDK Rate } \\
\text { Condition }\end{array}$} & \multirow{2}{*}{$\begin{array}{c}\text { DDK } \\
\text { Sequence }\end{array}$} & \multicolumn{5}{|c|}{ Fundamental Frequency $(\mathrm{Hz})$} \\
\cline { 3 - 8 } & & \multicolumn{4}{|c|}{ Male } & \multicolumn{3}{c|}{ Female } \\
\cline { 3 - 8 } & $\mathrm{p} \wedge$ & 113.89 & 16.07 & $95.3-151.67$ & 198.48 & 21.21 & $160.09-247.64$ \\
\hline \multirow{4}{*}{ Slow } & $\mathrm{p} \wedge$-tə & 114.28 & 16.38 & $92.63-156.05$ & 197.07 & 16.23 & $168.33-227.82$ \\
\cline { 2 - 9 } & $\mathrm{p} \wedge$-tə-kə) & 114.66 & 16.37 & $96.17-155.25$ & 199.22 & 20.07 & $159.36-231.78$ \\
\hline \multirow{3}{*}{ Comfortable } & $\mathrm{p} \wedge$ & 118.18 & 13.46 & $100.06-144.91$ & 197.50 & 25.19 & $153.21-230.09$ \\
\cline { 2 - 8 } & $\mathrm{p} \wedge$-tə & 113.99 & 14.07 & $98.71-146.24$ & 196.48 & 16.95 & $169.23-224.47$ \\
\cline { 2 - 8 } & $\mathrm{p} \wedge$-tə-kə & 116.80 & 14.42 & $96.66-151.62$ & 194.23 & 16.45 & $172.68-227.85$ \\
\hline \multirow{4}{*}{ Fast } & $\mathrm{p} \wedge$ & 121.04 & 14.03 & $98.96-146.77$ & 210.36 & 14.79 & $193.55-238.41$ \\
\cline { 2 - 8 } & $\mathrm{p} \wedge$-tə & 121.23 & 20.07 & $96.07-165.55$ & 200.36 & 15.03 & $177.73-229.41$ \\
\cline { 2 - 8 } & $\mathrm{p} \wedge$-tə-kə & 120.03 & 16.29 & $95.2-153.16$ & 203.98 & 17.02 & $173.6-231.27$ \\
\hline
\end{tabular}


DDK Rates, Frequency, and Intensity 34

Table 5: Probability values for post hoc pairwise t-test contrasts using the Tukey correction for DDK rates, syllables and sex for fundamental frequency.

\begin{tabular}{|c|c|c|c|c|c|}
\hline $\begin{array}{c}\text { Source of } \\
\text { Variance }\end{array}$ & Factors & $\mathrm{df}$ & $\begin{array}{c}\text { Mean } \\
\text { Squares }\end{array}$ & $\mathrm{F}$ & $\mathrm{p}$ \\
\hline \multirow{4}{*}{$\begin{array}{c}\text { Within } \\
\text { Subject }\end{array}$} & Rate & 2 & 1045.466 & 9.683 & $.000^{*}$ \\
\cline { 2 - 6 } & Error (Rate) & 44 & 107.972 & & \\
\cline { 2 - 6 } & Syllable & 2 & 132.736 & 3.080 & .056 \\
\cline { 2 - 6 } & Rate vs. Sex & 2 & 111.580 & 1.033 & .364 \\
\cline { 2 - 6 } & Syllable vs. Sex & 2 & 44.504 & 1.033 & .364 \\
\cline { 2 - 6 } & Rate vs. Syllable & 4 & 41.386 & .973 & .427 \\
\cline { 2 - 6 } & $\begin{array}{c}\text { Error (Rate vs. } \\
\text { Syllable) }\end{array}$ & 88 & 42.542 & & .007 \\
\cline { 2 - 6 } & $\begin{array}{c}\text { Rate vs. Syllable } \\
\text { vs. Sex }\end{array}$ & 4 & 78.479 & 1.845 & .127 \\
\hline \multirow{2}{*}{$\begin{array}{c}\text { Between } \\
\text { Subject }\end{array}$} & Sex & 1 & 368607.478 & 169.708 & $.000^{*}$ \\
\cline { 2 - 6 } & Error & 22 & 2172.008 & & \\
\hline
\end{tabular}

*Statistically significant $(\alpha=.05)$ 
DDK Rates, Frequency, and Intensity 35

Table 6: Pairwise comparisons of DDK rates, syllables and sex for fundamental frequency

\begin{tabular}{|c|c|c|c|c|c|}
\hline DDK Rates & $\mathrm{p}$ & DDK Syllables & $\mathrm{p}$ & Sex & $\mathrm{p}$ \\
\hline $\begin{array}{c}\text { Slow vs. } \\
\text { Comfortable }\end{array}$ & .953 & $\mathrm{p} \wedge$ vs. $\mathrm{p} \wedge$-tə & $.025^{*}$ & $\begin{array}{c}\text { Male vs. } \\
\text { Female }\end{array}$ & $.000^{*}$ \\
\hline Slow vs. Fast & $.004^{*}$ & $\mathrm{p} \wedge$ vs. $\mathrm{p} \wedge$-tə-kə & .140 & & \\
\hline Comfortable* Fast & $.002^{*}$ & $\mathrm{p} \wedge$-tə vs. $\mathrm{p} \wedge$-tə-kə & .380 & & \\
\hline
\end{tabular}

*Statistically significant $(\alpha=.05)$

Figure 4: Means and standard deviations for fundamental frequency $(\mathrm{Hz})$ for three rate conditions and three syllable complexity conditions for male and female participants.

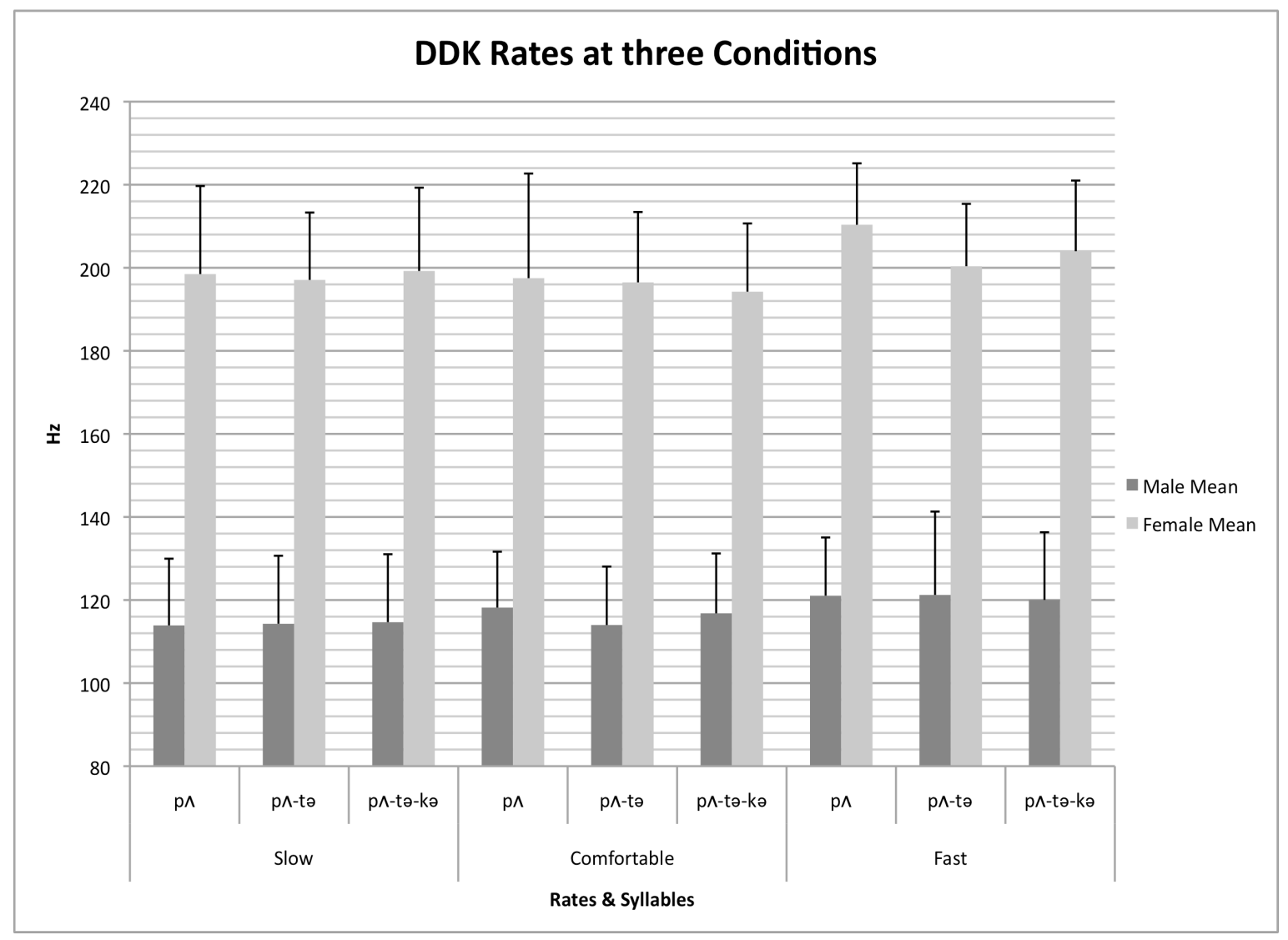


Figure 5: Mean fundamental frequency (Hz) for males for the three rate conditions averaged across the three syllable conditions.

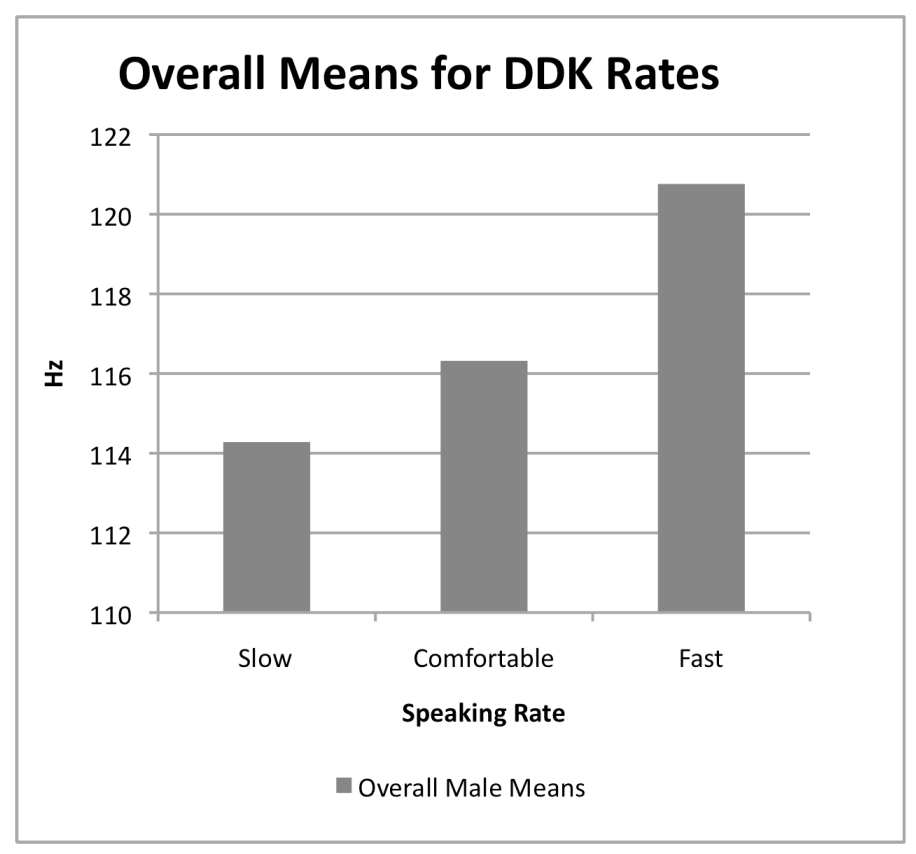

Figure 6: Mean fundamental frequency $(\mathrm{Hz})$ for females for the three rate conditions averaged across the three syllable conditions.

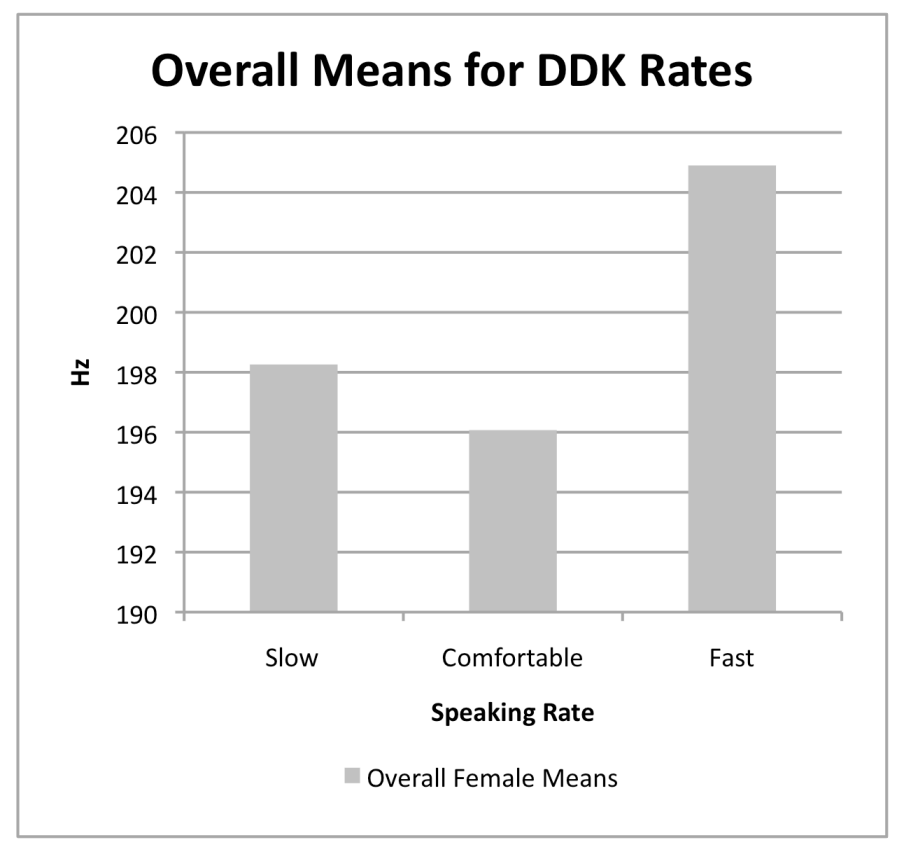


Figure 7: Mean fundamental frequency $(\mathrm{Hz})$ for males for the three syllable conditions averaged across the three rate conditions.

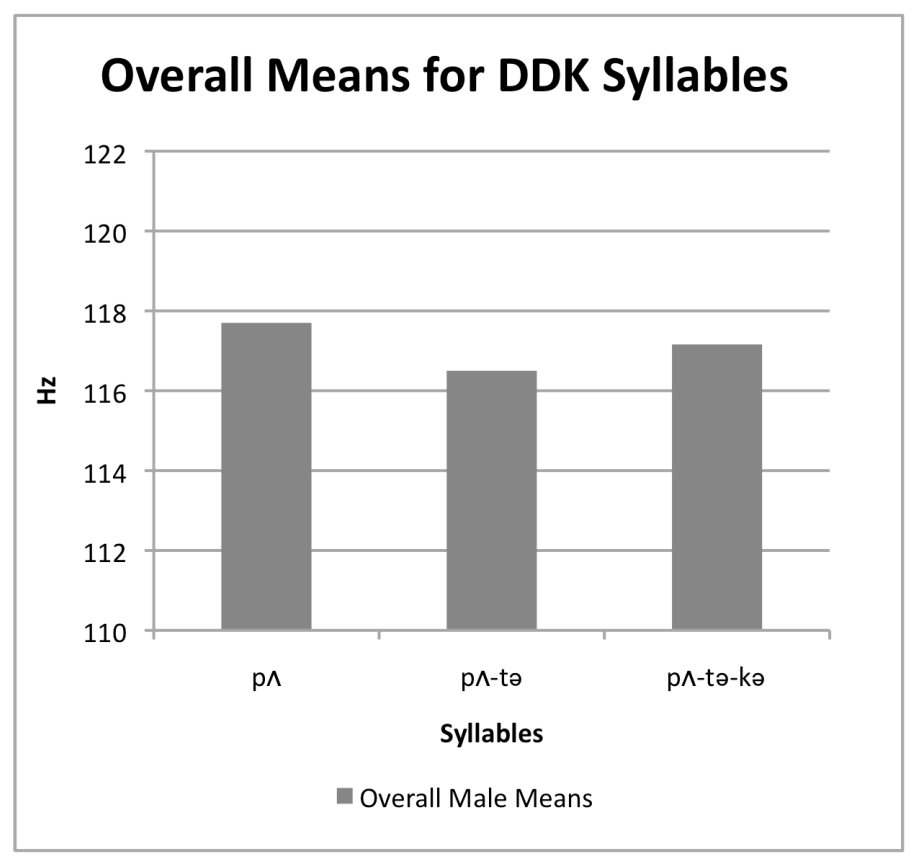

Figure 8: Mean fundamental frequency $(\mathrm{Hz})$ for females for the three syllable conditions averaged across the three rate conditions.

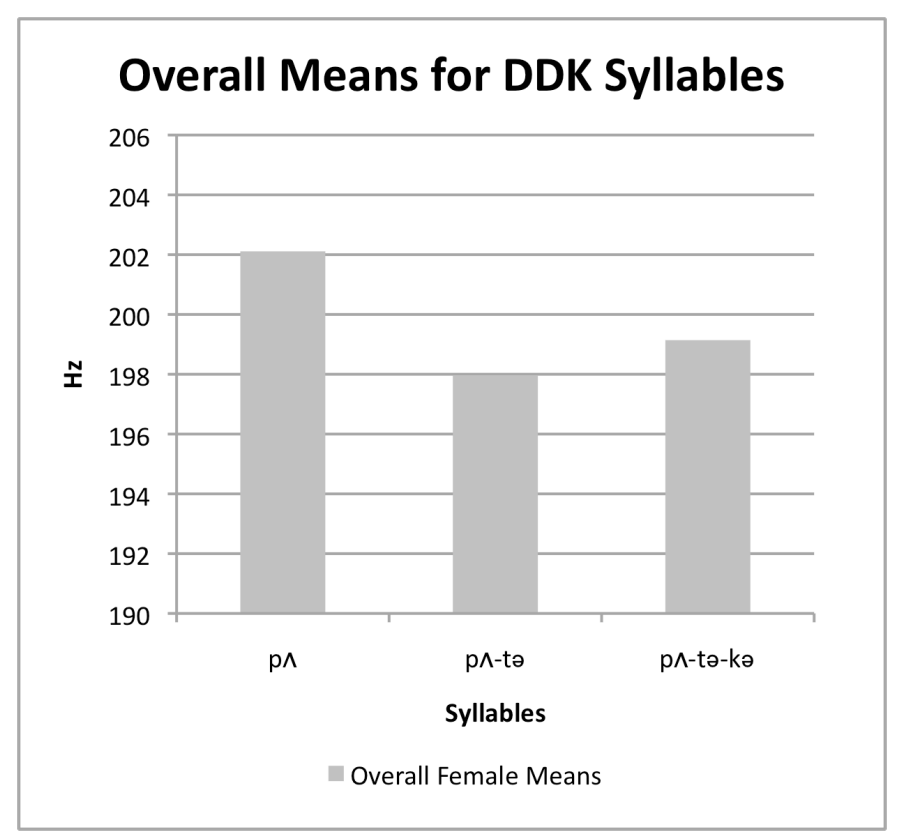


Average fundamental frequencies are $125 \mathrm{~Hz}$ for males and $225 \mathrm{~Hz}$ for females (Hollien, Hollien, \& de Jong, 1997). Overall male and female means in this study were 117 and 200, respectively, or slightly lower than averages, and more so for females. There was no doubt that females would have higher frequencies than males, as seen clearly in Figure 4, a result that obviously is highly significant $(\mathrm{p}<.001)$ (see below). Main effects are also shown in Figures 5 and 6 for males and females for rate and in Figures 7 and 8 for males and females for syllables.

The main effect for rate was statistically significant $(\mathrm{df}=2 ; \mathrm{F}=9.683 ; \mathrm{p}<.001)$ with no significant interactions as seen in Figures 5 and 6. For all participants, fundamental frequency increased about $6 \mathrm{~Hz}$ on average from slow to fast rates. Table 6 shows that that these differences were statistically significant in post hoc contrasts (slow to fast: $p=.004$; comfortable to fast: $p=.002$ ). Differences were not significant between slow and comfortable rates $(\mathrm{p}=.953)$.

Although there was not a significant effect for syllable tasks, it was close to being statistically significant $(\mathrm{p}=.056)$. The trend for a difference in fundamental frequency for syllables can be seen for both males and females in Figures 7 and 8 , where $\mathrm{p} \wedge$ resulted in the highest frequencies (117.70 and 202.11, respectively), followed by p^-tə-kə (117.16 and 199.14), and then by $\mathrm{p} \wedge$-tə (116.5 and 197.97). The post hoc contrast for $\mathrm{p} \wedge$ versus $\mathrm{p} \wedge$-tə was statistically significant $(\mathrm{p}=.025)$ (Table 6$)$. There were no syllable interactions (see Figures 7 and 8). 
DDK Rates, Frequency, and Intensity 39

\section{Vocal Intensity}

Vocal intensity was also measured using the CSL RTP program. Individual data for each participant are presented in the Appendix L. Means, standard deviations, and ranges for all DDK conditions are listed in Table 7 with means and standard deviations shown graphically in Figure 9. As before, main effects are shown in Figures 10 and 11, and statistical summaries in Tables 8 and 9 . 
Table 7: Means, standard deviations, and ranges for vocal intensity (dB SPL) for three rate conditions and three syllable complexity conditions for male and female participants.

\begin{tabular}{|c|c|c|c|c|c|c|c|}
\hline \multirow{3}{*}{$\begin{array}{c}\text { DDK Rates at } \\
\text { three } \\
\text { conditions }\end{array}$} & & \multicolumn{6}{|c|}{ Vocal Intensity (dB SPL) } \\
\hline & & \multicolumn{3}{|c|}{ Male } & \multicolumn{3}{|c|}{ Female } \\
\hline & & Mean & SD & Range & Mean & SD & Range \\
\hline \multirow{3}{*}{ Slow } & $\mathrm{p} \wedge$ & 65.30 & 3.05 & 58.64-69.41 & 61.20 & 2.53 & $56.27-66.28$ \\
\hline & $\mathrm{p} \wedge-\mathrm{ta}$ & 64.72 & 3.10 & 58.34-70.02 & 60.63 & 2.69 & $55.57-64.23$ \\
\hline & $\mathrm{p} \Lambda$-tə-kə & 64.55 & 2.92 & $57.57-68.27$ & 60.58 & 2.56 & $56.76-65.34$ \\
\hline \multirow{3}{*}{ Comfortable } & $\mathrm{p} \Lambda$ & 65.76 & 3.26 & $58.63-70.17$ & 61.90 & 2.53 & $57.34-66.4$ \\
\hline & p $\Lambda$-ta & 65.25 & 3.32 & $57.52-69.14$ & 60.58 & 3.07 & $54.9-64.48$ \\
\hline & $\mathrm{p} \Lambda-\mathrm{t} \partial-\mathrm{k} \partial$ & 64.79 & 2.45 & $58.96-68.11$ & 61.23 & 2.63 & $57.73-65.4$ \\
\hline \multirow{3}{*}{ Fast } & $\mathrm{p} \wedge$ & 63.82 & 3.77 & $57.63-69.07$ & 63.89 & 2.72 & $60.23-68.5$ \\
\hline & p $\wedge$-ta & 63.55 & 4.10 & $56.09-68.76$ & 62.57 & 3.56 & $57.3-68.58$ \\
\hline & pᄉ-tə-kə & 63.02 & 3.84 & $57.45-68.62$ & 60.87 & 3.60 & $56.19-66.39$ \\
\hline
\end{tabular}


Table 8: Probability values for post hoc pairwise t-test contrasts using the Tukey correction for DDK rates, syllables and sex for vocal intensity (dB SPL).

\begin{tabular}{|c|c|c|c|c|c|}
\hline $\begin{array}{l}\text { Source of } \\
\text { Variance }\end{array}$ & Factors & $\mathrm{df}$ & $\begin{array}{c}\text { Mean } \\
\text { Squares }\end{array}$ & $\mathrm{F}$ & $\mathrm{p}$ \\
\hline \multirow{8}{*}{$\begin{array}{l}\text { Within } \\
\text { Subject }\end{array}$} & Rate & 2 & 3.417 & .643 & .530 \\
\hline & Error (Rate) & 44 & 5.311 & & \\
\hline & Syllable & 2 & 24.214 & 9.443 & $.000 *$ \\
\hline & Error (Syllable) & 44 & 2.564 & & \\
\hline & Rate vs. Sex & 2 & 54.865 & 10.331 & $.000 *$ \\
\hline & Syllable vs. Sex & 2 & 2.244 & .875 & .424 \\
\hline & Rate vs. Syllable & 4 & 3.592 & 2.407 & .055 \\
\hline & $\begin{array}{c}\text { Rate vs. Syllable } \\
\text { vs. Sex }\end{array}$ & 4 & 3.614 & 2.422 & .054 \\
\hline \multirow{2}{*}{$\begin{array}{l}\text { Between } \\
\text { Subject }\end{array}$} & Sex & 1 & 497.072 & 7.458 & $.012^{*}$ \\
\hline & Error & 22 & 66.649 & & \\
\hline
\end{tabular}

*Statistically significant $(\alpha=.05)$

Table 9: Pairwise comparisons of DDK rates, syllables and sex for intensity (dB SPL).

\begin{tabular}{|c|c|c|c|c|c|}
\hline DDK Rates & $\mathrm{p}$ & DDK Syllables & $\mathrm{p}$ & Sex & $\mathrm{p}$ \\
\hline $\begin{array}{c}\text { Slow vs. } \\
\text { Comfortable }\end{array}$ & .224 & $\mathrm{p} \Lambda$ vs. $\mathrm{p} \wedge$-tə & $.010^{*}$ & $\begin{array}{c}\text { Male vs. } \\
\text { Female }\end{array}$ & $.012^{*}$ \\
\hline Slow vs. Fast & .783 & $\mathrm{p} \wedge$ vs. $\mathrm{p} \wedge$-tə-kə & $.001^{*}$ & & \\
\hline $\begin{array}{c}\text { Comfortable vs. } \\
\text { Fast }\end{array}$ & .406 & $\mathrm{p} \wedge$-tə vs. $\mathrm{p} \wedge$-tə-kə & .104 & & \\
\hline
\end{tabular}

*Statistically significant $(\alpha=.05)$ 
DDK Rates, Frequency, and Intensity 42

Figure 9: Means and standard deviations for vocal intensity (dB SPL) for three rate conditions and three syllable complexity conditions for male and female participants.

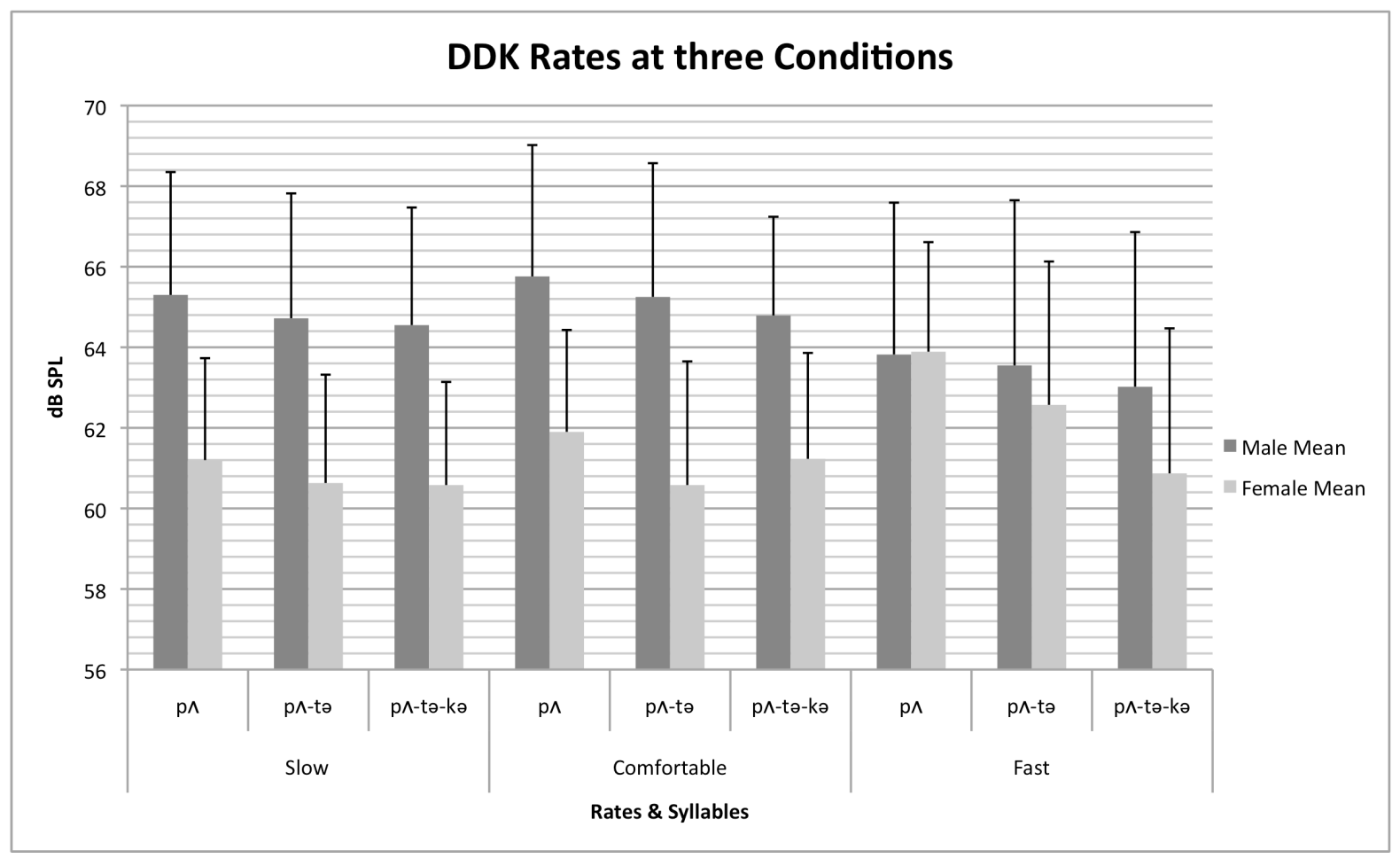


Figure 10: Mean intensity ( $d B S P L)$ for males and females for the three rate conditions averaged across the three syllable conditions.

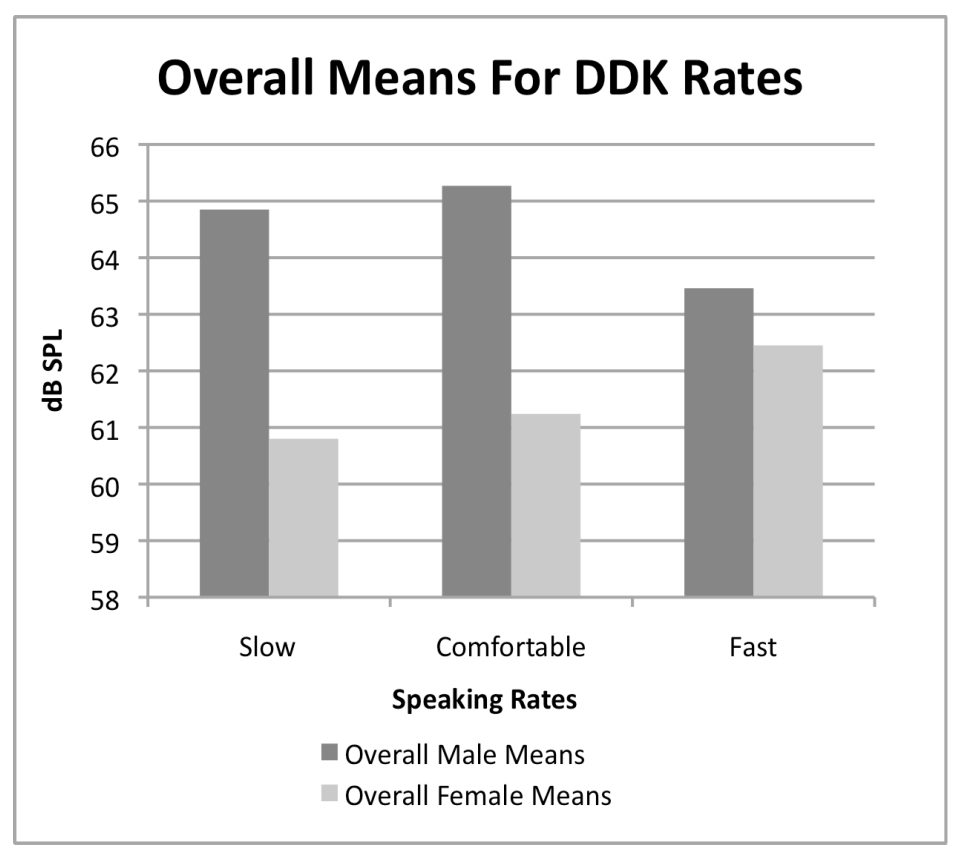

Figure 11: Mean intensity (dB SPL) for males and females for the three syllable conditions averaged across the three rate conditions.

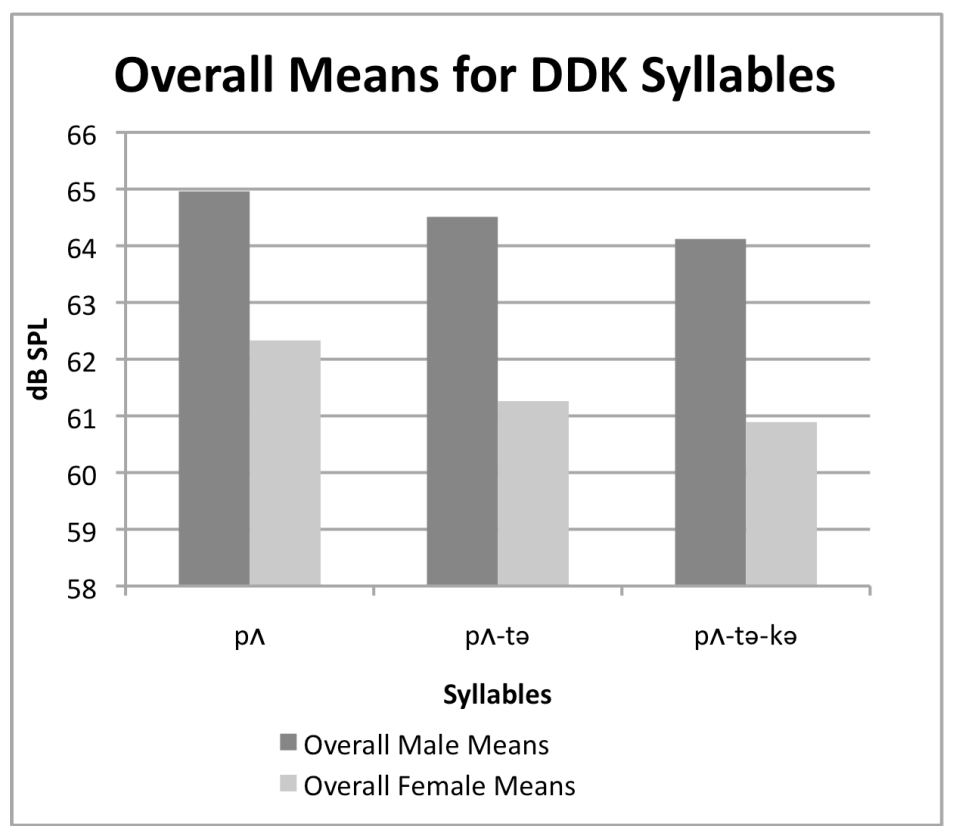


For intensity, MANOVA results (Table 8 ) did not reveal a main effect for rate $(\mathrm{p}=$ $.530)$, but there was a significant effect for syllables $(\mathrm{df}=2 ; \mathrm{F}=9.443 ; \mathrm{p}<.001)$. The intensity significantly decreased from $\mathrm{p} \wedge$ to $\mathrm{p} \wedge$-tə $(\mathrm{p}=.010)$ and from $\mathrm{p} \wedge$ to $\mathrm{p} \wedge$-tə-kə $(\mathrm{p}=$ $.001)$, but not from $\mathrm{p} \wedge$-tə to $\mathrm{p} \wedge$-tə-kə $(\mathrm{p}=.104)($ Table 9; Figure 11). There was also a significant difference between males and females overall in average vocal intensity as well that can be visualized in Figure 9.

In spite of no main effect for rate, the rate by sex interaction was found to be highly significant $(\mathrm{df}=2 ; \mathrm{F}=10.331 ; \mathrm{p}<.001)$. It is clear in Figure 10 that mean vocal intensity increased consistently from slow to comfortable, and from comfortable to fast for females. However, for males, it increased from slow to comfortable and decreased from comfortable to fast. In post hoc contrasts (Table 10), however, these differences were not statistically significant $(\mathrm{p}=.224$ to .783$)$.

The intensity analysis revealed complex interactions. The MANOVA procedure indicated that syllable by sex did not interact $(\mathrm{p}=.424)$; however, rate by syllable and rate by syllable by sex interactions were nearly significant $(p=.055$ and .054 , respectively). In Figure 9, for example, it can be seen that both males and females appeared to manifest their highest intensities in the fast rate for the syllable p^.

As shown in the Figure 10, for males, for all syllable tasks, intensity increased about $.40 \mathrm{~dB}$ from slow to comfortable rate, it decreased about $2 \mathrm{~dB}$ from comfortable to fast rate and it decreased about $1.5 \mathrm{~dB}$ from slow to fast rate. For females, for all syllables, the intensity increased $.40 \mathrm{~dB}$ from slow to comfortable rate, it increased about $1 \mathrm{~dB}$ from comfortable to fast rate, and it increased about $2 \mathrm{~dB}$ from slow to fast rates. Post hoc tests (Table 9) revealed that these were not significant differences. Nevertheless, 
these findings are consistent with the rate by syllable interaction: as the rate increased and the syllables became more complex, intensity was affected differently. It significantly decreased from $\mathrm{p} \wedge$ to $\mathrm{p} \wedge$-tə $(\mathrm{p}=.010)$ and from $\mathrm{p} \wedge$ to $\mathrm{p} \wedge$-tə-kə, $(\mathrm{p}=.001)$ but not from p^-tə to $\mathrm{p} \wedge$-tə-kə $(\mathrm{p}=.104)($ Table 9 ; Figure 11). 
DDK Rates, Frequency, and Intensity 46

\section{Discussion}

\section{Summary of Results}

The primary purpose of this study was to explore the influence of DDK rate on fundamental frequency and vocal intensity in young, healthy adults who had normal speech. It was hypothesized that their fundamental frequency and vocal intensity would be greatest at their maximum DDK rates and that these measures would be lower at slow or comfortable rates. One-, two-, and three-syllable DDK tasks were compared to measure the extent to which any changes in frequency or intensity as a function of speaking rate would differ across syllable complexity. Finally, the actual speed of speaking at each rate and syllable complexity level was measured as a control procedure.

As expected and as required by the design of this study, syllables per second as a measure of speaking speed significantly increased as the DDK rates increased from slow to comfortable and from comfortable to fast. Syllables per second also increased as a function of syllable complexity, i.e., from $\mathrm{p} \wedge$ to $\mathrm{p} \wedge$-tə and from $\mathrm{p} \wedge$ to $\mathrm{p} \wedge$-tə-kə, but not from $\mathrm{p} \wedge$-tə to $\mathrm{p} \wedge$-tə-kə. Rate interacted with syllables such that syllables per second (S/s) reflected different effects for rate and syllables as the DDK rates got faster and the syllables became more complex. No significant differences between males and females occurred for this measure. Conversely, there was a significant rate by sex interaction where females' speaking speed in syllables per second was noticeably slower than males'. 
As obviously expected, females had significantly higher fundamental frequencies than males. While the fundamental frequency did increase as the speaking rate became faster in both males and females, their vocal intensities did not change significantly as a function of rate.

A nonsignificant trend for fundamental frequency to differ according to syllable complexity was observed. As mentioned, there was not a significant effect for intensity as a function of rate; on the contrary, there was a significant effect for intensity as a function of syllable complexity. Intensity decreased from $\mathrm{p} \wedge$ to $\mathrm{p} \wedge$-tə and from $\mathrm{p} \wedge$ to $\mathrm{p} \wedge$-tə-kə, but not from $\mathrm{p} \wedge$-tə to $\mathrm{p} \wedge$-tə-kə.

Females were significantly softer (i.e., lower intensities) than males overall except for the syllable $\mathrm{p} \wedge$ at the fast rate. This explains a significant rate by sex interaction for intensity. Specifically, intensity increased from slow to fast rates for females. For males, however, intensity increased from slow to comfortable rates then decreased from comfortable to fast rates. It should be noted that these results were not significant in post hoc contrasts, probably because the interaction did not stop there. There were also nearly significant interactions for rate by syllable and rate by syllable by sex interactions. As the rates got faster and the syllables became more complex, intensity was affected differently; it decreased from $\mathrm{p} \wedge$ to $\mathrm{p} \wedge$-tə and from $\mathrm{p} \wedge$ to $\mathrm{p} \wedge$-tə-kə, but not from $\mathrm{p} \wedge$-tə to p^-tə-kə. In addition, again as the rate got faster and syllables got more complex, the intensity effect was different for males and females.

\section{Fundamental Frequency}

As expected, females were significantly higher than males in average fundamental frequency. However, the average fundamental frequency for these females was lower 
than findings from the literature (i.e., $200 \mathrm{~Hz}$ compared to a commonly reported average of $225 \mathrm{~Hz}$ ) (Hollien, Hollien, \& de Jong, 1997). Females were also found to be slightly slower than males in speaking speed in syllables per second and a little softer in vocal intensity (Figures 2, 6, and 10).

How can these results be explained? One possible explanation for the lower fundamental frequency is that as females' rate became slower, their vocal intensity became less intense, possibly to maintain sufficient speed to be able to repeat complex syllables. Due to the reduction in their intensity and speed, their fundamental frequency may also have dropped. Another explanation might relate to the testing environment during the experimental testing. During the testing sessions, females seemed less confident than males as noted by speaking quieter as they talked in the inclusion screening tasks and in repeating the DDK tasks. This was a subjective judgment by the author and for which there is no objective data; nevertheless, it could have influenced females' intensity and fundamental frequency to reduce.

Fundamental frequency was expected to increase as the rate increased from slow to fast rate and to be lower at comfortable and slow rates. For both males and females, these hypotheses were supported. Post hoc contrasts indicated that fundamental frequency increased from the slow to fast rate, and from comfortable to fast rates. By contrast, the slow and comfortable mean rate values for fundamental frequency were found to be very close and not significantly different.

To what extent are these findings consistent with the literature? The rate related increases in fundamental frequency support Saxena's (1992) findings of the highest fundamental frequencies at a fast rate of speech and the lowest during a slow rate. The 
increase in fundamental frequency for both males and females is not quite consistent with Dromey and Ramig's (1988) finding that fundamental frequency increased with faster rates in males. It might be recalled that the speaking task in the Dromey and Ramig study was repeating a sentence 10 times in various rate and intensity conditions. Inexplicably, these authors neither mentioned nor explained their females' frequency performance as a function of speaking rate.

For both males and females there was a nonsignificant syllable effect in the current study. The syllable $\mathrm{p} \wedge$ resulted in the highest fundamental frequencies, and they decreased significantly from $\mathrm{p} \wedge$ to $\mathrm{p} \wedge$-tə. On the contrary, there were no significant differences in fundamental frequency between $\mathrm{p} \wedge$ and $\mathrm{p} \wedge$-tə-kə and between $\mathrm{p} \Lambda$-tə and $\mathrm{p} \wedge$-tə-kə. For $\mathrm{p} \wedge$ to be the highest in frequencies may be related to coarticulation difference among the three tasks. Since the repetition of "p $\wedge$ " is formed using one bilabial

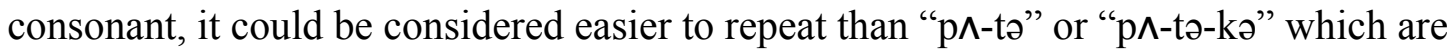
more complex and are formed by two and three different consonants. These findings provide limited support for the third hypothesis, i.e., that there are differences in fundamental frequency between three syllable groups although no statistically significant differences existed.

\section{Vocal Intensity}

It was also hypothesized that vocal intensity would increase as speaking rate got faster. Findings from this study revealed no significant effects in intensity as a function of rate increase. It does not, therefore, support (a) Dromey and Ramig's (1998) finding that mean intensity increased with rapid speech rate, (b) Wohlert and Hammen's (2000) 
findings that increases and decreases in speech rate accompanied with parallel changes in intensity, and (c) Linville, Skarin, and Fornatto's (1989) report that reading rate increased and decreased proportionally with fundamental frequency stability and maximum vocal intensity.

Two possible explanations can be advanced to interpret these inconsistencies. First, subglottal air pressure has a powerful influence on intensity increase (Baken \& Orlikoff, 2000), and large increases in vocal intensity are frequently accompanied by a deeper than normal breath. On the contrary, in the current study, participants were trained not to take a "deep" breath, but to take a "normal full" breath. This may have resulted in them generating lower subglottal air pressures and more constant vocal intensities than might have occurred without the instructions and training.

Second, consistent with Plant and Younger (2000) and Stathopoulos and Sapienza (1993), the intensity did not always increase and decrease as fundamental frequency did. It is likely, therefore, that in the DDK tasks used in this investigation, intensity and fundamental frequency were relatively independent of each other.

Females in this study were 1 to $2 \mathrm{~dB}$ softer (less intense) than males. Nevertheless the differences were minimal at the fast rate and virtually nonexistent for the syllable $\mathrm{p} \wedge$ at the fast rate. Were it not for this situation, the most reasonable explanation for this difference would be a difference in testing environment (i.e., a microphone placed slightly further away from the mouth). As an alternative explanation, the author draws attention to her subjective impression that female participants in general seemed less confident than male participants. They seemed more tentative and seemed to 
manifest softer speech when they spoke spontaneously, in oral reading, and in vowel production in the inclusion screening as well as in the DDK tasks.

Vocal intensity differed significantly for syllables. Specifically, intensity decreased as DDKs became more complex, i.e., from $\mathrm{p} \wedge$ to $\mathrm{p} \wedge$-to and from $\mathrm{p} \wedge$ to $\mathrm{p} \wedge$-tə-kə. There was no difference between $\mathrm{p} \wedge$-tə and $\mathrm{p} \wedge$-tə-kə. One possible explanation relates to phonotactic rules. When English speakers produce word-initial voiceless stops, they aspirate them. The p^-tə and $\mathrm{p} \wedge$-tə-kə sequences are not words, but they are typically produced like words phonotactically, i.e., the first voiceless stop is aspirated much more than the subsequent stops. If the CSL program were affected by the energy from aspiration, then six instances of aspiration in $\mathrm{p} \wedge$ would generate higher intensities compared to three $\mathrm{p} \Lambda^{\prime} \mathrm{s}$ in three sets of $\mathrm{p} \Lambda$-tə or two $\mathrm{p} \wedge^{\prime} \mathrm{s}$ in two sets of $\mathrm{p} \wedge$-tə-kə.

A second possible explanation for vocal intensity differences among the DDK sequences relates to maintaining and releasing air pressure for voiceless stops. While producing rapid repetitions of $\mathrm{p} \wedge$, speakers use only their lips as consonant articulators. Rapid movements of lips may more efficiently utilize subglottal air pressure than alternating movement requiring use of the lips and tongue or lips, tongue and velum. When speakers repeat more complex syllables $\mathrm{p} \wedge$-tə and $\mathrm{p} \wedge$-tə-kə, more air may be lost with concurrent decreases in subglottal air pressure. If so, the intensity might be expected to decrease.

A third explanation for the DDK difference relates to the syllable stress. Stress refers to differential emphasis on words or syllables during speech. Physiologically stress helps punctuate speech through intensity, frequency, and duration changes. To increase the stress on a word or a syllable, speakers increase subglottal air pressure, glottal tension 
and, therefore, intensity and fundamental frequency (Seikel, Drumright, \& Seikel, 2004).

In this study, the syllable p $\wedge$ had the highest intensities in all DDK rates, which was followed by $\mathrm{p} \wedge$-tə, then followed by $\mathrm{p} \wedge$-tə-kə. Between these nonsense syllables, $\mathrm{p} \wedge$ has the most stress (six occurrences), followed by p $\wedge$-tə (three occurrences), and then followed by p^-tə-kə (two occurrences), which might explain the increased intensities for the syllable $\mathrm{p} \wedge$ in all DDK levels.

Another significant finding in the current study was a rate by sex interaction for intensity. Males' intensity increased from slow to comfortable and decreased from comfortable to fast, whereas females' intensity consistently increased from slow to comfortable to fast. Importantly, these increases in females were not significant.

\section{Interaction of Fundamental Frequency and Vocal Intensity}

Shanks' (1970) exploration of the relationship between changes in pitch and loudness and rates of syllable repetitions relates to this present study even though Shanks' methodology was quite different. Shanks found that speaking rates were the highest at participants' comfortable pitch and loudness levels. Rates for Shanks' participants were slower as loudness was reduced at comfortable pitches. With high loudness at low pitches, the rates became significantly slower, and at high pitches, the rates significantly increased as phonation became louder. It must be recalled that participants in that study selected their own rates, which limits the degree to which their results can be compared to this study. Nevertheless, in the present study, fundamental frequencies were highest at the fast rates for both males and females, which does not support Shanks' first finding. By contrast, it supports Shanks' second finding that at 
comfortable rates, the fundamental frequency was lower. Another current finding also does not quite support the Shanks' finding that at high pitches, rates increased as the loudness increased. In this study, fundamental frequency increased at the fast rates, but the intensity did not show a significant increase.

The findings of this study for fundamental frequency partly support Plant and Younger's (2000) findings that at high intensities, as the subglottal air pressure increased and fundamental frequency also increased. At low intensities fundamental frequency was independent from subglottal air pressure. In this study, although fundamental frequency increased as a function of rate increase, the overall intensity stayed about the same. The only effect of intensity on rate was in a rate by sex interaction. Comparing the current study to Plant and Younger's study, their finding of parallel increases in subglottal air pressure and fundamental frequency at high intensities is not supported, but there is limited support for the independence of fundamental frequency and subglottal air pressure (as the primary determinant of intensity) at low intensities.

Perhaps the reason for the independence of frequency and intensity in the current study was that fundamental frequency or intensity increases were not large in either males or females. Participants presumably had sufficient breath support to support continued repetitions of the syllables without being too loud. Participants were told to start with a full speaking breath, but, not a "deep" breath. Since they were trained not to take a deep breath, their subglottal air pressure mechanism may not have played a role in their frequency changes as they increased to their maximum rates. This interpretation is consistent with the report of Baken and Orlikoff (2000) that vocal frequency change is only minimally related to subglottal air pressure. Overall, this study supports the 
independence of fundamental frequency increases from changes in subglottal air pressure, roughly similar to the interpretation of Plant and Younger (2000).

In Stathopoulos and Sapienza's (1993) study, fundamental frequency increased when all the children and adult groups went from soft to loud speech. Additionally, in adult women and men, fundamental frequency increased when they spoke at comfortable intensity compared to soft speech. This is obliquely related to the present study. In this study, for males, the fundamental frequency increased from slow to fast speaking rates. By contrast, intensity did not significantly increase; remaining within about $1 \mathrm{~dB}$, from slow to fast rates, where the fundamental frequency increased by $6 \mathrm{~Hz}$. These findings roughly support Stathopoulos and Sapienza's (1993) findings suggesting an intensity decrease when fundamental frequency increased. For females, in this current study, the intensity increased slightly (about $2 \mathrm{~dB}$ ) from slow to fast rates, while the fundamental frequency increased about $6 \mathrm{~Hz}$. Although, these differences were not significant in the post hoc results for females, it explains the different effect in males and females in the rate by sex interaction.

Stathopoulos and Sapienza (1993) also found that subglottic air pressure decreased as the fundamental frequency increased from comfortable to soft speech. A similar phenomenon may have characterized the females in this study; i.e., a slight intensity increase in females as the subglottic air pressure decreased. If so, this provides some added support for the independence of fundamental frequency and intensity; e.g., Plant and Younger's findings that at low intensities, fundamental frequency was independent from subglottic air pressure. 
DDK Rates, Frequency, and Intensity 55

\section{Integration of Results}

What caused fundamental frequency to increase as a function of rate?

Rapid, repetitive movements likely caused the vocal muscles to become tenser which in turn produced an increase in fundamental frequency (Hanson, 2008; Boone, McFarlane, \& Von Berg, 2005). As a result, longitudinal tension and medial compression of the vocal folds appears to have increased as speaking rates increased.

What caused intensity to remain more or less constant especially when fundamental frequency increased at faster rates? The literature suggests that intensity and frequency both often increase with more rapid speaking rates, but not uniformly so. The participants in this study were told "not to take a deep breath, but to take a normal full breath," which likely resulted in preventing the intensity to increase. As a result, the rapid syllable repetition tasks in this study, requiring 10 seconds of DDK productions in each task, motivated the participants unconsciously to moderate their intensity, so they could finish without running out of breath. Accordingly, as explained in the foregoing discussion, fundamental frequency increases were probably independent of the intensity changes in this study. 
DDK Rates, Frequency, and Intensity 56

\section{Speaking Speed in Syllables per Second}

Speaking speed in syllables per second significantly increased as a function of rate increase as anticipated in the current study. Means for slow rates were $0.8 \mathrm{~S} / \mathrm{s}, 1.6 \mathrm{~S} / \mathrm{s}$ for comfortable rates, and $6.3 \mathrm{~S} / \mathrm{s}$ for fast rates. Means for $\mathrm{p} \wedge$ were $2.6 \mathrm{~S} / \mathrm{s}, 3.1 \mathrm{~S} / \mathrm{s}$ for $\mathrm{p} \Lambda$ to, and 3.0 S/s for p $\Lambda$-tə-kə across all DDK rate levels. These confirm findings from Baken and Orlikoff's (2000) summary of DDK norms showing approximately $6.0 \mathrm{~S} / \mathrm{s}$ on average for maximum rates for DDK syllables. The means stated above also confirm the St. Louis and Ruscello (2000) findings of DDK norms showing 2.9, 3.4, and 3.6 rates in seconds on average in maximum rates, for $\mathrm{p} \wedge, \mathrm{p} \wedge$-tə and $\mathrm{p} \wedge$-tə-kə, respectively. The normative data showed no differences as a function of sex. Baken and Orlikoff's summaries indicate expected rates of $7.0 \mathrm{~S} / \mathrm{s}$ and $6.9 \mathrm{~S} / \mathrm{s}$ for males and females for $\mathrm{p} \Lambda$, and $5.8 \mathrm{~S} / \mathrm{s}$ and $6.3 \mathrm{~S} / \mathrm{s}$ for males and females for $\mathrm{p} \wedge-t$ - $-\mathrm{k}$. In this study, a significant rate by sex interaction occurred wherein females were slower than males overall, noticeably for the fast rate. In spite of the noticeable slowness of females, the means for both sexes are within Baken and Orlikoff's (2000) normative range. Rates for males in the current study were a little higher than Baken and Orlikoff's summary for maximum p^-tə-kə rates, $5.8 \mathrm{~S} / \mathrm{s}$ versus $6.6 \mathrm{~S} / \mathrm{s}$.

Syllables per second increased from $\mathrm{p} \wedge$ to $\mathrm{p} \wedge$-tə; and from $\mathrm{p} \wedge$ to $\mathrm{p} \wedge$-tə-kə; but not from $\mathrm{p} \wedge$-tə to $\mathrm{p} \wedge$-tə-kə. Nevertheless, another interaction occurred for rates by syllables. As the syllables per second increased from slow to comfortable to fast, different effects were observed with basic and more complex syllables. 


\section{Limitations and Future research}

One limitation in this study was the fact that the vocal intensity was not calibrated with a sound level meter, Therefore, the author cannot be absolutely certain that the microphone was recording exactly the frequencies and intensities that were produced by the participants. Nevertheless, there was no indication in the data that such a measurement artifact occurred.

The DDK tasks utilized in the study cannot be generalized to normal speech. Moreover, the DDK tasks themselves may have produced some unexpected artifacts. For example, the author observed that a few participants jumbled up the fast $\mathrm{p} \wedge$-tə or $\mathrm{p} \wedge$-to-kə sequences such that they were excluded and the trial repeated. In some of these instances, the participants began the subsequent task a little slower and then increased to a much faster rate. Subjectively, it appeared that as they progressively increased without stopping, there was a noticeable increase in their pitch. Therefore, one way to modify the tasks for future studies could be for participants to start at a slow or a comfortable rate for a few seconds and then on signal within the same breath cycle increase to their maximum repetition rate. Starting at a maximum rate and dropping progressively to a slower rate might also be a useful parallel task to document effects of rate changes on fundamental frequency and intensity. 
DDK Rates, Frequency, and Intensity 58

\section{Conclusion}

The main purpose of this study was to explore the effect of speaking rate on fundamental frequency and intensity. The hypothesis, that fundamental frequency would increase as a function of rate increase was supported. The parallel hypothesis for intensity was not supported; as DDK rates increased, intensity remained more or less constant. The results of this study provide empirical support for a long unsupported report that speech rate is an important variable in voice evaluations. They also contribute to a small body of research on the complex interactions of vocal fundamental frequency, intensity, and speaking rate that has important ramifications for better understanding of voice and speech science. Future research should continue to explore the effects of speaking rate on fundamental frequency and intensity and the vocal mechanisms that underlie them. 
DDK Rates, Frequency, and Intensity 59

\section{References}

Abitbol, J., Abitbol, R., \& Abitbol, B. (1999). Sex hormones and the female voice. Journal of Voice, 13, 3.

American Speech-Language-Hearing Association Audiological Assessment Panel 1996. (1997). Guidelines for audiological screening. Rockville, MD: Author.

Atkinson, J. E. (1978). Correlation analysis of the physiological factors controlling fundamental voice frequency. Journal of the Acoustical Society of America, 63, 211-222.

Baken, R. J., \& Orlikoff, R. F. (2000). Clinical measurement of speech and voice $\left(2^{\text {nd }}\right.$ ed.). San Diego, CA: Singular.

Baken R. J., \& Orlikoff, R. F. (1987). Phonatory response to step function changes in supraglottal pressure. In T. Baer, C. Sasaki, \& K. S. Harris (Eds.), Laryngeal function in phonation and respiration (pp. 273-290). Boston, MA: College-Hill Press.

Barreto, S. S., \& Ortiz, K. Z. (2008). Influence of speech rate and loudness on speech intelligibility. Pró-fono : Revista de atualização científica, 20 (2), 87-92.

Boone, D. R., McFarlane, S. C., \& Von Berg, S. L. (2005). The voice and the voice therapy. Boston: Pearson Education.

Calvert, D. R., \& Silverman, S. R. (1975). Speech and deafness. Washington, DC: Alexander Graham Bell Association for the Deaf.

Costello, J. M., \& Ingham, R. J. (1984). Assessment strategies for stuttering. In R. Curlee \& W. Perkins (Eds.), Nature and treatment of stuttering: New directions (pp. 303333). San Diego, CA: College-Hill Press. 
Dromey, C., \& Ramig, L. O. (1998). Intentional changes in sound pressure level and rate: Their impact on measures of respiration, phonation, and articulation. Journal of Speech, Language, and Hearing Research, 41, 1003-1018.

Duffy, J. (2005). Motor speech disorders. St. Louis, MO: Elsevier Mosby.

Fairbanks, G. (1960). Voice and articulation drillbook. New York, NY: Harper \& Row.

Fletcher, S. G. (1972). Time-by-count measurement of diadochokinetic syllable rate. Journal of Speech and Hearing Research, 15, 763-770.

Gay, L. R., Mills, G. E., \& Airasian, P. (2006). Educational research: Competencies for analysis and applications. Upper Saddle River, NJ: Pearson Prentice Hall.

Gelfand, S. A. (2007). Hearing: An introduction to psychological and physiological acoustics. New York, NY: Informa Healthcare.

Guitar, B. (2006). Stuttering. Baltimore: Lippincott Williams \& Wilkins.

Hall, K. D., \& Yairi, E. (1992). Fundamental frequency, jitter, and shimmer in preschoolers who stutter. Journal of Speech and Hearing Research, 35, 10021008.

Hanson, H. M. (2008). Effects of obstruent consonants on fundamental frequency at vowel onset in English. Journal of the Acoustical Society of America, 125, 425441.

Hollien, H., Hollien, P. A., \& de Jong, G. (1997). Effects of three parameters on speaking fundamental frequency. Journal of the Acoustical Society of America, 102, 29842992.

Hutchinson, B. B., Hanson, M. L., \& Mecham M. J. (1979). Diagnostic handbook of speech pathology. Baltimore; Williams \& Wilkins. 
DDK Rates, Frequency, and Intensity 61

Isshiki, N. (1964). Regulatory mechanism of voice intensity variation. Journal of Speech and Hearing Research, 7, 17-29.

Kay Pentax (2008a). Multi-Speech and Computerized Speech Lab Software Instruction Manual. Lincoln Park, NJ: A Division of PENTAX Medical Company.

Kay Pentax (2008b). Real-Time Pitch (RTP) Software Instruction Manual. Lincoln Park, NJ; A Division of PENTAX Medical Company.

Linville, S., Skarin, B., \& Fornatto, E. (1989). The interrelationship of measures related to vocal function, speech rate, and laryngeal appearance in elderly women. Journal of Speech and Hearing Research, 32, 323-330.

Lundy, D., Roy, S., Xue, J., Casiano, \& D., Jassir. (2004). Spastic/spasmodic vs. tremulous vocal quality: Motor speech profile analysis. Journal of Voice, 18, 146152.

Martin, R. R., Haroldson, S. K., \& Triden, K. A. (1984). Stuttering and speech naturalness. Journal of Speech and Hearing Disorders, 49, 53-58.

Nie, H. N \& Hull, C. H. (1968). SPSS [computer software]. Chicago, IL: SPSS Inc, IBM. Orlikoff, R. F., \& Kahane, J. C. (1996). Structure and function of the larynx. In N. J. Lass (Ed.), Principles of Experimental Phonetics (pp. 113-181). St. Louis, MO: Mosby-Year Book.

Peterson, H. A., \& Marquardt, T. P. (1981). Appraisal and diagnosis of speech and language disorders. Englewood Cliffs, NJ: Prentice-Hall.

Pindzola, R. H., Jenkins, M. M., \& Lokken, K. J. (1989). Speaking rates of young children. Language, Speech, and Hearing Services in Schools, 20, 133-138. 
Pindzola, R. H. (1987). A Voice Assessement Protocol for Children and Adults. Austin, TX: PRO-ED.

Plant, P., \& Younger, R. (2000). The interrelationship of subglottic air pressure, fundamental frequency and vocal intensity during speech. Journal of Voice, 14 , 170-177.

Raphael, L., Borden, G., \& Harris, K. (2007). Speech science primer (5th ed). Baltimore: Lippincott Williams \& Wilkins.

Sawyer, J., Chon, H., \& Ambrose, N. (2008). Influences of rate, length, and complexity on speech disfluency on a single-speech sample in preschool children who stutter. Journal of Fluency Disorders, 33, 220-240.

Saxena, P. (1992). The effect of speaking rate on the vocal intensity and $\mathrm{F}_{\boldsymbol{o}}$ topline. Psycho-Lingua, 22, 51-56.

Schulz, G. M. (2002). The effects of speech therapy and pharmacological treatment on voice and speech in Parkinson's disease: A review of the literature. Current Medicinal Chemistry, 9, 1359-1366.

Seikel, J. A., Drumright, D., \& Seikel, P. (2004). Essentials of anatomy and physiology for communication disorders. Clifton Park: Thomson and Delmar Learning.

Shanks, S. (1970). Effect of variations in pitch and loudness upon rapid syllable repetitions. Perceptual and Motor Skills, 30, 739- 744.

Stathopoulos, E. T., \& Sapienza, C. (1993). Respiratory and laryngeal measures of children during vocal intensity variation. Journal of the Acoustical Society of America, 94 (5), 2531-2543. 
Stemple, C. J., Glaze, L.E., \& Klaben, B. G. (2000). Clinical voice pathology: Theory and management. San Diego, CA: Singular Publishing Group.

Stoicheff, M. L. (1981). Speaking fundamental frequency characteristics of nonsmoking female adults. Journal of Speech and Hearing Research, 24, 437-441.

Sturm, J. A., \& Seery, C. H. (2007). Speech and articulatory rates of school-aged children in conversation and narrative contexts. Language, Speech and Hearing Services in Schools, 38, 47-59.

St. Louis, K. O., \& Ruscello, D. M. (2000). Oral Speech Mechanism Screening Examination ( ${ }^{\text {rd }}$ ed). Austin, TX: PRO-ED.

St. Louis, K., Myers, F., Faragasso, K., Townsend, P., \& Gallaher, A. (2004). Perceptual aspects of cluttered speech. Journal of Fluency Disorders, 29, 213-235.

Titze, I. R. \& Sundberg, J. (1992). Vocal intensity in speakers and singers. Journal of the Acoustical Society of America, 91, 2936-2946.

Watson, P. J., Ciccia, A. H., \& Weismer, G. (2003). The relation of lung volume initiation to selected acoustic properties of speech. Journal of the Acoustical Society of America, 113, 2812-2819.

Wilson, K. (1979). Voice problems of children. Baltimore: Williams \& Wilkins. Wohlert, A., \& Hammen, V. (2000). Lip muscle activity related to speech rate and loudness. Journal of Speech, Language and Hearing Research, 43, 1229-1239. 
Appendix A. Voice related questions asked of all potential participants.

Age

1. Have you ever had / Do you have a physical problem that affects your tongue, lip, mouth or throat? $\square$ No $\square$ Yes. If yes, please explain.

2. Have you ever had/ Do you have a problem with breathing? $\square$ No $\square$ Yes. If yes, please explain.

3. Have you ever had any professional voice/singing lessons? $\square$ No $\square$ Yes. If yes, please describe.

4. (a) How often do you sing?

(b) Where do you sing?

(c) How much singing do you do?

(c1) None

(c2) 5 minutes a day or less

(c3) 5 - 10 minutes a day

(c4) 10 - 20 minutes a day

(c5) 20 - 30 minutes a day

(c6) 30 minutes -1 hour a day

(c7) More than 1 hour a day

5. Have you ever professionally involved in athletics? No Yes. If yes, please describe.

6. Have you ever / Do you play a wind musical instrument? No Yes. If yes, what instrument? 
Appendix B. Individual participants' responses to voice related questions.

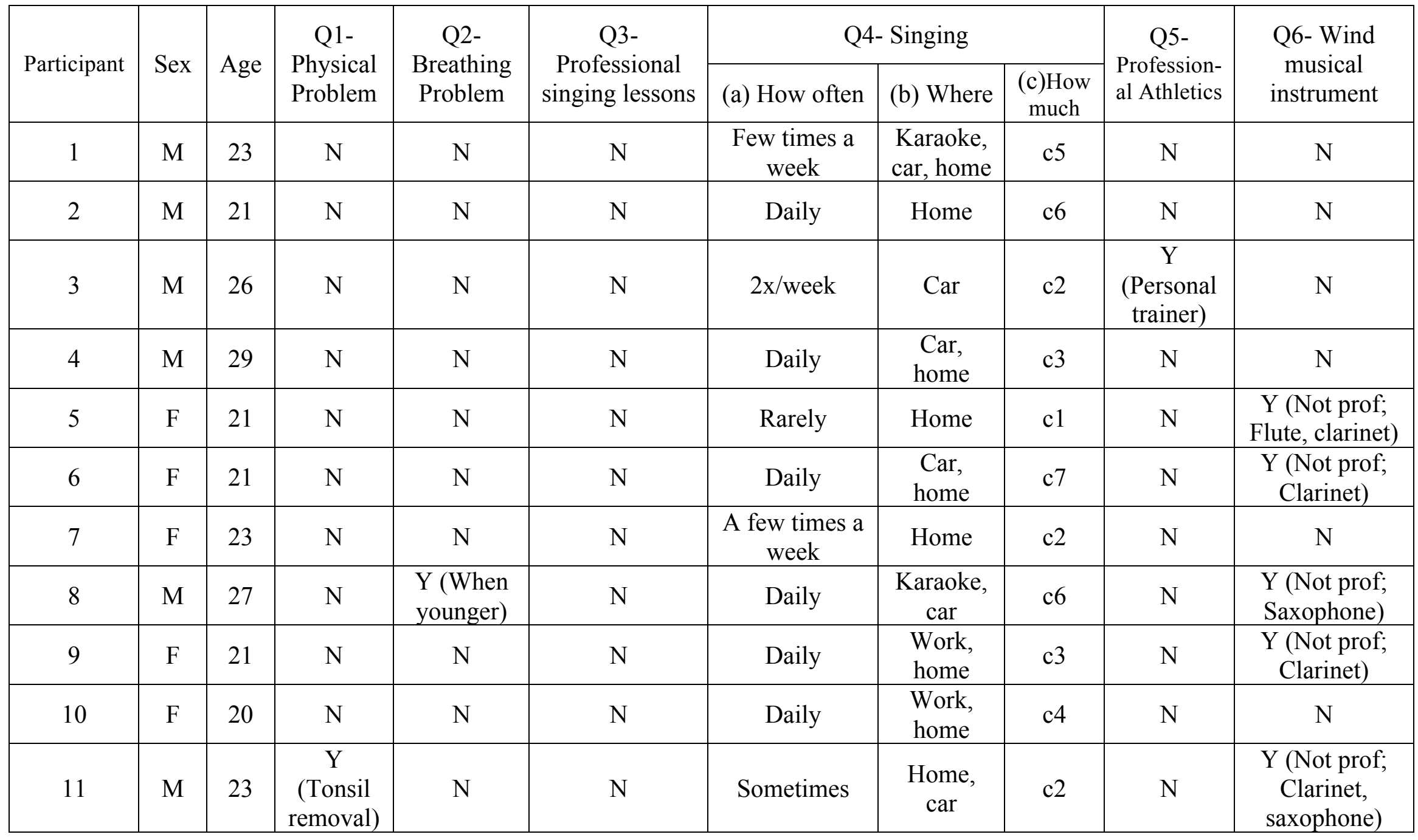


DDK Rates, Frequency, and Intensity 66

\begin{tabular}{|c|c|c|c|c|c|c|c|c|c|c|}
\hline 12 & M & 23 & $\mathrm{~N}$ & $\mathrm{~N}$ & $\mathrm{~N}$ & Sometimes & $\begin{array}{c}\text { Home, } \\
\text { car }\end{array}$ & $\mathrm{c} 4$ & $\mathrm{~N}$ & $\begin{array}{c}\text { Y (Not prof; } \\
\text { Saxophone, } \\
\text { clarinet) }\end{array}$ \\
\hline 13 & $\mathrm{~F}$ & 23 & $\mathrm{~N}$ & $\mathrm{~N}$ & $\begin{array}{l}\text { N (Not prof; } \\
\text { choir traning } \\
\text { in high school) }\end{array}$ & Sometimes & $\begin{array}{l}\text { Home, } \\
\text { car }\end{array}$ & $\mathrm{c} 5$ & $\mathrm{~N}$ & $\mathrm{~N}$ \\
\hline 14 & M & 20 & $\mathrm{~N}$ & $\mathrm{~N}$ & $\mathrm{~N}$ & Never & None & $\mathrm{c} 1$ & $\mathrm{~N}$ & $\begin{array}{c}\text { Y (Not prof; } \\
\text { Saxophone, } \\
\text { clarinet) }\end{array}$ \\
\hline 15 & $\mathrm{~F}$ & 24 & $\mathrm{~N}$ & $\mathrm{~N}$ & $\begin{array}{l}\text { N (Not prof; } \\
\text { church choir) }\end{array}$ & Often & $\begin{array}{l}\text { Car, } \\
\text { home }\end{array}$ & c3 & $\begin{array}{c}\text { Y (Karate, } \\
\text { dance) }\end{array}$ & $\mathrm{N}$ \\
\hline 16 & M & 21 & $\mathrm{~N}$ & $\mathrm{~N}$ & $\mathrm{~N}$ & Daily & $\begin{array}{l}\text { Car, } \\
\text { home }\end{array}$ & $\mathrm{c} 2$ & $\mathrm{~N}$ & $\mathrm{~N}$ \\
\hline 17 & M & 22 & $\mathrm{~N}$ & $\mathrm{~N}$ & $\mathrm{~N}$ & Never & None & $\mathrm{c} 1$ & $\mathrm{~N}$ & $\mathrm{~N}$ \\
\hline 20 & $\mathrm{~F}$ & 20 & $\mathrm{~N}$ & $\mathrm{~N}$ & $\mathrm{~N}$ & Rarely & Home & $\mathrm{c} 2$ & $\mathrm{~N}$ & $\mathrm{~N}$ \\
\hline 21 & $\mathrm{~F}$ & 21 & $\mathrm{~N}$ & $\begin{array}{l}\text { Y (mild; } \\
\text { childhood) }\end{array}$ & $\mathrm{N}$ & Sometimes & $\begin{array}{l}\text { Home, } \\
\text { car }\end{array}$ & c3 & $\mathrm{N}$ & $\mathrm{N}$ \\
\hline 22 & M & 22 & $\mathrm{~N}$ & $\mathrm{~N}$ & $\mathrm{~N}$ & Rarely & $\begin{array}{l}\text { Car, } \\
\text { home }\end{array}$ & $\mathrm{c} 2$ & $\mathrm{~N}$ & $\mathrm{~N}$ \\
\hline 23 & $\mathrm{~F}$ & 23 & $\mathrm{~N}$ & $\mathrm{~N}$ & $\mathrm{~N}$ & Daily & $\begin{array}{l}\text { Home, } \\
\text { car }\end{array}$ & $\mathrm{c} 4$ & $\mathrm{~N}$ & $\mathrm{~N}$ \\
\hline 24 & $\mathrm{~F}$ & 28 & $\mathrm{~N}$ & $\mathrm{~N}$ & $\begin{array}{c}\mathrm{N} \text { (brief } \\
\text { training in } \\
\text { middle school) }\end{array}$ & Rarely & Home & $\mathrm{c} 1$ & $\mathrm{~N}$ & $\mathrm{~N}$ \\
\hline
\end{tabular}


DDK Rates, Frequency, and Intensity 67

Appendix C. Perceptual screening criteria that the author and two speech-language pathology graduate students filled for all participants.

Perceptual Screening Form

\begin{tabular}{llll} 
Name & Birth Date & Age & Sex \\
Rater & Date & \\
\hline
\end{tabular}

1. Articulation $\quad$ Pass $\quad$ Fail

2. Language $\quad$ Pass $\quad$ Fail

3. Fluency Pass $\quad$ Fail

4. Resonance

Pass Fail

5. Pitch Pass Fail

6. Loudness

Pass

Fail

7. Quality

Pass

Fail

8. Rate

Pass

Fail 
DDK Rates, Frequency, and Intensity 68

Appendix D. Air conduction hearing screening all potential participants underwent.

Pure Tone Hearing Screening Form

Name

Birth Date

Age Sex

Date

Right Ear

\begin{tabular}{|c|c|c|c|c|c|}
\hline $20 \quad \mathrm{~dB}$ & 1000 & $2000 \mathrm{~Hz}$ & 3000 & 4000 & $\mathrm{~Hz}$ \\
\hline $\begin{array}{l}\text { Pass (P)/ } \\
\text { Fail (F) }\end{array}$ & & & & & \\
\hline
\end{tabular}

Left Ear

\begin{tabular}{|c|c|c|c|c|c|}
\hline $20 \quad \mathrm{~dB}$ & 1000 & $2000 \mathrm{~Hz}$ & 3000 & 4000 & $\mathrm{~Hz}$ \\
\hline $\begin{array}{l}\text { Pass (P)/ } \\
\text { Fail (F) }\end{array}$ & & & & & \\
\hline
\end{tabular}


Appendix E. Reliability summary from the author and one or two independent judges of all participants on the perceptual screening form. "P" indicates "pass"; " $F$ " indicates "fail."

\begin{tabular}{|c|c|c|c|c|c|c|c|c|c|}
\hline $\begin{array}{c}\text { Criteria } \\
\text { Participants }\end{array}$ & $\begin{array}{c}1 . \\
\text { Artic }\end{array}$ & $\begin{array}{c}2 . \\
\text { Lang } \\
\end{array}$ & $\begin{array}{c}3 . \\
\text { Fluency }\end{array}$ & $\begin{array}{c}4 . \\
\text { Resonance } \\
\end{array}$ & $\begin{array}{c}5 . \\
\text { Pitch } \\
\end{array}$ & $\begin{array}{c}6 . \\
\text { Loudness }\end{array}$ & $\begin{array}{c}7 . \\
\text { Quality }\end{array}$ & $\begin{array}{r}8 . \\
\text { Rate } \\
\end{array}$ & $\mathrm{P} / \mathrm{F}$ \\
\hline 1 & PP & PP & PP & PP & PP & PP & PP & PP & $\mathrm{P}$ \\
\hline 2 & PP & PP & PP & PP & PP & PP & PP & PP & $\mathrm{P}$ \\
\hline 3 & PP & PP & PP & PP & PP & PP & PP & PP & $\mathrm{P}$ \\
\hline 4 & PP & PP & FFF & PP & PP & PP & PP & PP & $\mathrm{F}$ \\
\hline 5 & PP & PP & PP & PP & PP & PP & PP & PP & $\mathrm{P}$ \\
\hline 6 & PP & PP & PP & PP & PP & PP & PP & PP & $\mathrm{P}$ \\
\hline 7 & PP & PP & PP & PP & PP & PP & PP & PP & $P$ \\
\hline 8 & PP & PP & PP & PP & PP & PP & PP & PP & $P$ \\
\hline 9 & $\mathrm{PP}$ & PP & PP & PP & PP & PP & PP & PP & $\mathrm{P}$ \\
\hline 10 & PP & PP & $\mathrm{PP}$ & PP & PP & PP & PP & PP & $\mathrm{P}$ \\
\hline 11 & PP & PP & PP & PP & PP & PP & PP & $\mathrm{PP}$ & $\mathrm{P}$ \\
\hline 12 & PP & PP & FFF & PP & FFF & PP & FFF & PP & $\mathrm{F}$ \\
\hline 13 & PP & PP & PP & PP & PP & PP & PP & PP & $\mathrm{P}$ \\
\hline 14 & PP & PP & PP & PP & PP & PP & PP & PP & $\mathrm{P}$ \\
\hline 15 & PP & PP & PP & PP & PP & PP & PP & PP & $\mathrm{P}$ \\
\hline 16 & PP & PP & PP & PP & PP & PP & PP & PP & $\mathrm{P}$ \\
\hline 17 & PP & PP & PP & PP & PP & PP & PP & PP & $\mathrm{P}$ \\
\hline 18 & PP & $\mathrm{PP}$ & $\mathrm{PP}$ & $\mathrm{PP}$ & PP & PP & PP & PP & $\mathrm{P}$ \\
\hline 19 & PP & PP & $\mathrm{PP}$ & $\mathrm{PP}$ & PP & PP & PP & $\mathrm{PP}$ & $\mathrm{P}$ \\
\hline 20 & PP & PP & PP & PP & PP & PP & PP & PP & $\mathrm{P}$ \\
\hline 21 & PP & PP & PP & PPF & PP & PP & PFF & PP & $\mathrm{F}$ \\
\hline 22 & PP & PP & PP & PP & PP & PP & PP & PP & $\mathrm{P}$ \\
\hline 23 & PP & PP & PP & PP & PP & PP & PP & PP & $\mathrm{P}$ \\
\hline 24 & PP & PP & PP & PP & PP & PP & PP & PP & $\mathrm{P}$ \\
\hline 25 & PP & PP & PP & PP & PP & PP & PP & PP & $\mathrm{P}$ \\
\hline 26 & PP & PP & PP & PP & PP & PP & PP & PP & $\mathrm{P}$ \\
\hline 27 & PP & PP & PP & PP & PP & PP & PP & PP & $\mathrm{P}$ \\
\hline
\end{tabular}


Appendix F. Script of the experimental procedures given to all participants by the author.

\section{Providing Informed Consent}

\section{Script of the Experimental Procedures}

Now. I am going to put this (the head-mount) microphone on your head. It hooks

your ears so that it won't move. Try not to shake your head. Make sure it's comfortable and please do NOT touch it. If it is uncomfortable and needs to be adjusted, please let me know before we start the study. Now, is it comfortable for the next 30 minutes?

Now, can you say count to five and right after that hold out the sound /a/ a few times until I tell you to stop like this when I say "Go." (Model "1,2,3,4,5 /a/- 1,2,3,4,5 /a/, 1,2,3,4,5 /a/") (Turn up/down the microphone volume until it's appropriate.) And you can take a breath if you need.

Or say the Pledge of Allegiance.

Before we start, I am going to ask you a few questions.

What is your full name?

What is your major?

Can you tell me a little bit about your major?

Where are you from?

Can you describe your hometown or the city or town where you now live?

Please read this passage out loud (The Rainbow Passage) (Fairbanks, 1960).

OK. Now, hold out the sound /a/ until I tell you to stop like this when I say "Go." (/a/ for 5 seconds.) Are you ready? Go! Stop.

Now, hold out the sound /u/ when I say "go"? Are you ready? Go! Stop. 
OK. We are ready to start. You are going to be repeating groups of syllables. Try to complete each group in one breath. Please sit up straight, but also be comfortable. Take a FULL breath like this (Demonstrate) before you start each group, but do NOT take a deep breath like this. (Demonstrate.). Just take a full breath when you start like this. (Demonstrate.)

Here is the syllable "puh" as in "pun." [Show "puh" on a card. Take them away.] Now, repeat "puh" at your comfortable speaking rate until I say stop? Are you ready? Go!... Stop.

Here are two syllables "puh" and "tuh." [Show "puh" on one card and "tuh" on another card. Take them away.] Put those two syllables together and repeat them at your comfortable speaking rate until I say stop? Are you ready? Go!... Stop.

Here are three syllables "puh," "tuh," and "kuh," [Show "puh," "tuh," and "kuh," on three separate cards. Take them away.] Put those three syllables together and repeat them at your comfortable speaking rate until I say stop? Are you ready? Go!... Stop.

Now, here's the syllable "puh" as in "pun". I am going to repeat it slowly. (I will model "puh" at a rate of one syllable per second for about 10 seconds.) Now repeat "puh" slowly just like I did. Are you ready? Go!.... Stop. 
Here are the syllables "puh" and "tuh". I am going to repeat them slowly. (I will model "puh-tuh" at a rate of one syllable per second for about 10 seconds.) Now, repeat "puh-tuh" slowly just like I did. Are you ready? Go!.... Stop.

Here are the syllables "puh," "tuh" and "kuh." I am going to repeat them slowly. (I will model "puh-tuh" at a rate of one syllable per second for about 10 seconds.) Now, repeat "puh-tuh-kuh" slowly just like I did. Are you ready? Go!.... Stop.

We'll now do these all again at a fast speed.

First, repeat "puh-puh-puh-puh..." as fast as you can. Let's try it first. (Example. If $\mathrm{OK}$, go on. If too slow, train to say it a near maximum rate. If too fast or too strained, train to say it at a little less than maximum rate.) Are you ready? Go!... Stop.

Now, repeat "puh-tuh-puh-tuh-puh-tuh..." as fast as you can. (model the "flap t). Let's try it first. (Example. If OK, go on. If too slow, train to say it a near maximum rate. If too fast or too strained, train to say it at a little less than maximum rate.) Try to make the syllables distinct but do not exaggerate them. Are you ready? Go!... Stop.

Finally, repeat "puh-tuh-kuh-puh-tuh-kuh-puh-tuh-kuh...” (model the "flap t”) (modeled fast) as fast as you can. Let's try it first. (Example. If OK, go on. If too slow, train to say it a near maximum rate. If too fast or too strained, train to say it at a little less than maximum rate.) Just go on till you run out of air or until I say stop. Are you ready? Go!... Stop. 
DDK Rates, Frequency, and Intensity 73

Appendix G. The paragraph all participants read to meet the inclusion criteria from the perceptual screening form.

\section{The Rainbow Passage}

When the sunlight strikes raindrops in the air, they act as a prism and form a rainbow. The rainbow is a division of white light into many beautiful colors. These take the shape of a long round arch, with its path high above, and its two ends apparently beyond the horizon. There is, according to legend, a boiling pot of gold at one end. People look, but no one ever finds it (Fairbanks, 1960). 
Appendix H. The selection of the syllables with cursors within one breath cycle in three DDK rates for the fundamental frequency, and intensity measurements.

Analysis within Breath Cycle

Hypothetical Speaker

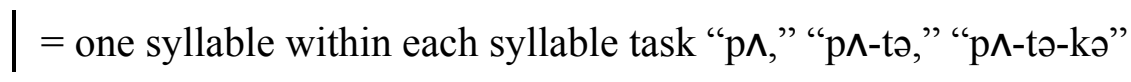

【= cursors for the measured syllables

Start

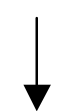

7-8 seconds

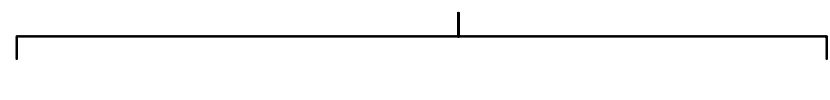

Slow Rate

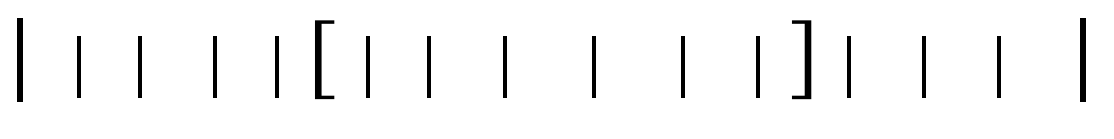

$7-8$ seconds

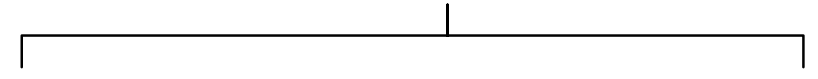

Comfortable Rate ||||||||$[||||||]||||||||$

7-8 seconds

Fast Rate

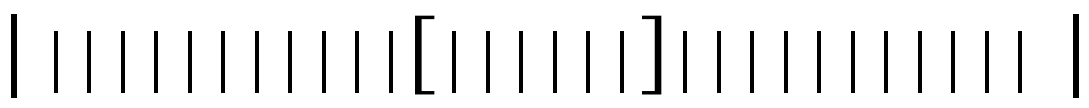


DDK Rates, Frequency, and Intensity 75

Appendix I. Ages of matched pairs of male and female participants

\begin{tabular}{|c|c|}
\hline Male Ages & Female Ages \\
\hline 23 & 21 \\
\hline 23 & 20 \\
\hline 27 & 24 \\
\hline 21 & 21 \\
\hline 26 & 23 \\
\hline 20 & 21 \\
\hline 23 & 20 \\
\hline 21 & 22 \\
\hline 22 & 23 \\
\hline 23 & 21 \\
\hline 23 & 21 \\
\hline 29 & 28 \\
\hline Average & Average \\
\hline 23.42 & 22.08 \\
\hline
\end{tabular}




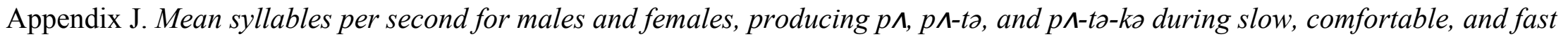
rates.

\begin{tabular}{|c|c|c|c|c|c|c|c|c|c|}
\hline Syllables/second & \multicolumn{3}{|c|}{ Slow } & \multicolumn{3}{|c|}{ Comfortable } & \multicolumn{3}{|c|}{ Fast } \\
\hline Participants & $\mathrm{p} \wedge$ & $\mathrm{p} \wedge$-to & $\mathrm{p} \wedge-\mathrm{t}$ - $\mathrm{k} \partial$ & $\mathrm{p} \wedge$ & $\mathrm{p} \wedge$-tə & $\mathrm{p} \wedge$-tə-kə & $\mathrm{p} \wedge$ & $\mathrm{p} \wedge$-tə & $\mathrm{p} \wedge$-tə-kə \\
\hline Male 1 & 0.78 & 0.80 & 0.82 & 1.50 & 1.71 & 1.86 & 4.71 & 9.60 & 6.50 \\
\hline Male 2 & 0.73 & 0.73 & 0.67 & 1.11 & 1.27 & 1.20 & 6.50 & 9.25 & 6.50 \\
\hline Male 3 & 0.73 & 0.91 & 0.92 & 2.50 & 2.50 & 2.10 & 5.25 & 7.56 & 8.25 \\
\hline Male 4 & 1.00 & 1.00 & 1.09 & 2.63 & 2.71 & 2.44 & 6.63 & 7.75 & 7.50 \\
\hline Male 5 & 0.80 & 0.91 & 0.90 & 1.25 & 1.56 & 1.91 & 4.75 & 7.00 & 6.13 \\
\hline Male 6 & 0.67 & 0.91 & 1.09 & 2.50 & 1.30 & 1.36 & 7.00 & 5.71 & 4.88 \\
\hline Male 7 & 0.62 & 1.00 & 1.00 & 1.10 & 1.75 & 1.80 & 6.83 & 5.71 & 5.86 \\
\hline Male 8 & 0.90 & 0.89 & 0.92 & 1.63 & 1.50 & 1.50 & 7.00 & 5.67 & 7.67 \\
\hline Male 9 & 0.73 & 0.89 & 0.92 & 1.11 & 1.75 & 1.67 & 3.13 & 8.00 & 6.80 \\
\hline Male 10 & 0.82 & 0.77 & 0.86 & 1.71 & 1.27 & 2.33 & 4.75 & 8.33 & 6.14 \\
\hline Male 11 & 0.80 & 0.73 & 0.82 & 2.00 & 1.33 & 1.50 & 6.29 & 8.57 & 8.00 \\
\hline Male 12 & 0.78 & 0.62 & 0.64 & 1.38 & 1.10 & 1.33 & 4.63 & 7.14 & 6.14 \\
\hline Female 1 & 0.82 & 0.64 & 0.69 & 2.00 & 1.11 & 1.15 & 5.63 & 6.89 & 7.13 \\
\hline Female 2 & 0.90 & 0.83 & 0.86 & 1.56 & 1.56 & 1.71 & 4.60 & 7.43 & 8.00 \\
\hline Female 3 & 0.89 & 0.71 & 0.69 & 2.14 & 1.80 & 1.09 & 5.50 & 7.33 & 5.25 \\
\hline Female 4 & 0.70 & 0.71 & 0.79 & 1.63 & 1.11 & 1.10 & 5.71 & 5.43 & 6.00 \\
\hline Female 5 & 0.70 & 1.00 & 1.00 & 1.44 & 1.56 & 2.00 & 4.57 & 5.33 & 6.33 \\
\hline Female 6 & 0.67 & 0.91 & 1.00 & 1.10 & 1.57 & 1.67 & 4.33 & 6.63 & 5.14 \\
\hline Female 7 & 0.69 & 0.80 & 0.79 & 1.33 & 2.29 & 2.00 & 5.38 & 8.29 & 7.00 \\
\hline Female 8 & 0.90 & 0.73 & 0.75 & 1.63 & 1.20 & 1.20 & 5.50 & 5.75 & 5.67 \\
\hline Female 9 & 0.70 & 0.89 & 0.90 & 1.13 & 1.75 & 1.88 & 5.00 & 6.75 & 5.57 \\
\hline Female 10 & 0.89 & 0.73 & 0.75 & 1.75 & 1.33 & 1.33 & 6.25 & 6.75 & 7.13 \\
\hline Female 11 & 0.78 & 0.80 & 1.00 & 2.67 & 2.00 & 2.00 & 5.83 & 7.71 & 6.50 \\
\hline Female 12 & 0.70 & 0.62 & 0.75 & 1.38 & 1.33 & 1.36 & 5.50 & 6.22 & 7.00 \\
\hline Overall Mean & 0.78 & 1.67 & 5.47 & 0.81 & 1.60 & 7.12 & 0.86 & 1.65 & 6.54 \\
\hline St Dev & 0.10 & 0.81 & 0.86 & 0.51 & 1.60 & 1.65 & 0.96 & 7.12 & 6.54 \\
\hline
\end{tabular}


DDK Rates, Frequency, and Intensity 77

Appendix K. Fundamental frequency measures for males and females, producing $p \wedge, p \wedge-t \partial$, and p^-tə-ka during slow, comfortable, and fast rates.

\begin{tabular}{|c|c|c|c|c|c|c|c|c|c|}
\hline & \multicolumn{3}{|c|}{$\mathrm{p} \wedge$} & \multicolumn{3}{|c|}{$\mathrm{p} \wedge$-tə } & \multicolumn{3}{|c|}{ p^-tə-kə } \\
\hline & Slow & Comfortable & Fast & Slow & Comfortable & Fast & Slow & Comfortable & Fast \\
\hline Male 1 & 103.56 & 104.84 & 110.51 & 106.28 & 102.74 & 106.18 & 105.4 & 103.66 & 108.15 \\
\hline Male 2 & 127.42 & 121.85 & 128.71 & 123.31 & 124.32 & 133.7 & 130.26 & 118.08 & 129.36 \\
\hline Male 3 & 126.18 & 142.21 & 137.02 & 123.33 & 119.33 & 133.22 & 124.47 & 124.46 & 130.16 \\
\hline Male 4 & 108.58 & 110.74 & 114.06 & 109.89 & 101.51 & 123.71 & 110.53 & 110.85 & 108.23 \\
\hline Male 5 & 103.63 & 109.23 & 98.96 & 104.63 & 101.07 & 96.07 & 105.87 & 110.65 & 99.85 \\
\hline Male 6 & 151.67 & 144.91 & 146.77 & 156.05 & 146.24 & 165.55 & 155.25 & 151.62 & 153.16 \\
\hline Male 7 & 105.65 & 116.29 & 108.03 & 108.94 & 114.06 & 111.22 & 103.89 & 114.67 & 117.1 \\
\hline Male 8 & 95.35 & 100.06 & 106.75 & 97.2 & 101.13 & 96.8 & 97.48 & 102.54 & 95.2 \\
\hline Male 9 & 122.96 & 116.34 & 117.85 & 120.6 & 117.85 & 101.82 & 111.54 & 122.48 & 113.49 \\
\hline Male 10 & 113.17 & 121.54 & 125.55 & 109.82 & 125.68 & 124.17 & 117.27 & 127.74 & 133.67 \\
\hline Male 11 & 113.17 & 117.18 & 127.18 & 118.66 & 115.25 & 127.87 & 117.82 & 118.15 & 129.03 \\
\hline Male 12 & 95.3 & 112.95 & 131.04 & 92.63 & 98.71 & 134.42 & 96.17 & 96.66 & 122.97 \\
\hline Female 1 & 210.66 & 216.49 & 205.84 & 199.32 & 200.4 & 213.11 & 208.21 & 207.13 & 225.33 \\
\hline Female 2 & 193.78 & 188.34 & 218.65 & 192.14 & 193.37 & 202.67 & 191.59 & 185.96 & 193.65 \\
\hline Female 3 & 191.2 & 153.21 & 196.19 & 178.72 & 180.83 & 180.03 & 188.59 & 188.11 & 200.21 \\
\hline Female 4 & 210.69 & 224.3 & 229.32 & 205.95 & 217.82 & 197.77 & 213.23 & 215.34 & 210.81 \\
\hline Female 5 & 179.88 & 186.85 & 208.68 & 189.49 & 184.72 & 209.88 & 183.53 & 180.89 & 190.9 \\
\hline Female 6 & 193.07 & 205.6 & 199.16 & 195.61 & 189.12 & 191.68 & 199.48 & 185.25 & 195 \\
\hline Female 7 & 202.46 & 187.18 & 193.55 & 197.07 & 201.84 & 195.33 & 198.77 & 180.59 & 196.65 \\
\hline Female 8 & 160.09 & 156.53 & 197.19 & 168.33 & 169.23 & 177.73 & 159.36 & 172.68 & 173.6 \\
\hline Female 9 & 247.64 & 230.09 & 238.41 & 227.82 & 219.75 & 229.41 & 231.78 & 227.85 & 231.27 \\
\hline Female 10 & 209.76 & 225 & 222.05 & 221.69 & 224.47 & 213.53 & 230.69 & 206.28 & 224.23 \\
\hline Female 11 & 185.72 & 192.26 & 196.82 & 194.26 & 189.51 & 187.97 & 190.4 & 194.95 & 193.58 \\
\hline Female 12 & 196.8 & 204.13 & 218.44 & 194.48 & 186.65 & 205.16 & 195.01 & 185.74 & 212.48 \\
\hline Total means & 156.18 & 157.84 & 165.70 & 155.68 & 155.23 & 160.79 & 156.94 & 155.51 & 162.00 \\
\hline St Dev & 46.96 & 45.07 & 47.75 & 45.19 & 44.80 & 43.98 & 46.75 & 42.34 & 45.87 \\
\hline
\end{tabular}


DDK Rates, Frequency, and Intensity 78

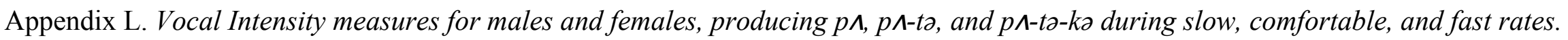

\begin{tabular}{|c|c|c|c|c|c|c|c|c|c|}
\hline & \multicolumn{3}{|c|}{$\mathrm{p} \wedge$} & \multicolumn{3}{|c|}{$\mathrm{p} \wedge$-tə } & \multicolumn{3}{|c|}{ p^-tə-kə } \\
\hline & Slow & Comfortable & Fast & Slow & Comfortable & Fast & Slow & Comfortable & Fast \\
\hline Male 1 & 65.56 & 65.57 & 65.97 & 65.05 & 65.02 & 63.76 & 65.18 & 65.2 & 64.75 \\
\hline Male 2 & 66.54 & 68.01 & 69.07 & 65.09 & 67.46 & 68.76 & 67.91 & 66.19 & 68.42 \\
\hline Male 3 & 69.41 & 69 & 66.73 & 69.23 & 69.14 & 67.29 & 68.27 & 67.51 & 67.37 \\
\hline Male 4 & 65.12 & 61.8 & 58.06 & 65.63 & 62.44 & 56.09 & 64.16 & 62.63 & 59.7 \\
\hline Male 5 & 64.09 & 70.17 & 64.51 & 63.31 & 67.55 & 64.43 & 62.94 & 64.89 & 61.05 \\
\hline Male 6 & 68.11 & 65.36 & 61.51 & 65.69 & 62.04 & 60.15 & 62.71 & 63.98 & 61.9 \\
\hline Male 7 & 69.18 & 68.22 & 66.61 & 70.02 & 69.08 & 67.47 & 68.08 & 65.59 & 68.62 \\
\hline Male 8 & 65.8 & 67.1 & 67.12 & 65.4 & 66.65 & 66.27 & 64.73 & 68.11 & 65.43 \\
\hline Male 9 & 61.93 & 66.35 & 61.4 & 62.72 & 64.65 & 61.28 & 63.56 & 66.67 & 61.23 \\
\hline Male 10 & 63.53 & 63.13 & 60.93 & 61.99 & 66.18 & 61.88 & 64.76 & 63.45 & 57.45 \\
\hline Male 11 & 58.64 & 58.63 & 57.63 & 58.34 & 57.52 & 57.97 & 57.57 & 58.96 & 58.3 \\
\hline Male 12 & 65.65 & 65.82 & 66.24 & 64.12 & 65.3 & 67.29 & 64.74 & 64.3 & 62.04 \\
\hline Female 1 & 60.98 & 61.83 & 64.12 & 61.17 & 59.62 & 62.4 & 59.95 & 59.83 & 57.78 \\
\hline Female 2 & 63.37 & 61.13 & 66.86 & 60.99 & 60.21 & 59.06 & 59.16 & 60.51 & 56.19 \\
\hline Female 3 & 66.28 & 65.55 & 68.5 & 64.23 & 63.48 & 68.11 & 65.34 & 64.27 & 64.67 \\
\hline Female 4 & 59.65 & 59.95 & 60.47 & 59.96 & 58.3 & 60.61 & 57.47 & 58.75 & 60.96 \\
\hline Female 5 & 62.54 & 62.45 & 62.55 & 62.1 & 63.19 & 63.25 & 61.86 & 64.44 & 63.17 \\
\hline Female 6 & 61.87 & 63.62 & 66.45 & 62.15 & 63.36 & 65.99 & 62.58 & 63.56 & 64.75 \\
\hline Female 7 & 60.88 & 60.41 & 61.93 & 60.76 & 56.65 & 59.56 & 61.27 & 59.43 & 56.5 \\
\hline Female 8 & 61.8 & 63.12 & 64.07 & 64.11 & 64.48 & 63.97 & 63.6 & 65.4 & 64.03 \\
\hline Female 9 & 59.72 & 61.14 & 62.16 & 58.42 & 60.94 & 61.49 & 58.76 & 61.11 & 59.96 \\
\hline Female 10 & 58.63 & 59.88 & 62.49 & 55.57 & 54.9 & 57.3 & 58.75 & 57.73 & 58.19 \\
\hline Female 11 & 56.27 & 57.34 & 60.23 & 56.46 & 58.56 & 60.54 & 56.76 & 58.13 & 57.87 \\
\hline Female 12 & 62.43 & 66.4 & 66.88 & 61.64 & 63.24 & 68.58 & 61.41 & 61.61 & 66.39 \\
\hline Total means & 63.25 & 63.83 & 63.85 & 62.67 & 62.92 & 63.06 & 62.56 & 63.01 & 61.95 \\
\hline St Dev & 3.45 & 3.47 & 3.22 & 3.52 & 3.93 & 3.79 & 3.37 & 3.08 & 3.80 \\
\hline
\end{tabular}

